\title{
A Thermal Skin Model for Comparing Contact Skin Temperature Sensors and Assessing Measurement Errors
}

\author{
Braid A. MacRae ${ }^{1,2,3}{ }^{D}$, Christina M. Spengler ${ }^{2,4}{ }^{\text {, Agnes Psikuta }}{ }^{1}$, René M. Rossi ${ }^{1}$ (D) and Simon Annaheim ${ }^{1, *(D)}$ \\ 1 Empa, Swiss Federal Laboratories for Materials Science and Technology, Laboratory for Biomimetic \\ Membranes and Textiles, 9014 St. Gallen, Switzerland; braid.macrae@rmit.edu.au (B.A.M.); \\ agnes.psikuta@empa.ch (A.P.); rene.rossi@empa.ch (R.M.R.) \\ 2 Exercise Physiology Lab, Department of Health Sciences and Technology, ETH Zurich, \\ 8057 Zurich, Switzerland; christina.spengler@hest.ethz.ch \\ 3 Centre for Materials Innovation and Future Fashion, School of Fashion and Textiles, RMIT University, \\ Melbourne 3056, Australia \\ 4 Zurich Center for Integrative Human Physiology (ZIHP), University of Zurich, 8057 Zurich, Switzerland \\ * Correspondence: simon.annaheim@empa.ch
}

Citation: MacRae, B.A.; Spengler, C.M.; Psikuta, A.; Rossi, R.M.;

Annaheim, S. A Thermal Skin Model for Comparing Contact Skin Temperature Sensors and Assessing Measurement Errors. Sensors 2021, 21, 4906. https://doi.org/10.3390/ s21144906

Academic Editor: James F. Rusling

Received: 27 May 2021

Accepted: 14 July 2021

Published: 19 July 2021

Publisher's Note: MDPI stays neutral with regard to jurisdictional claims in published maps and institutional affiliations.

Copyright: (c) 2021 by the authors. Licensee MDPI, Basel, Switzerland. This article is an open access article distributed under the terms and conditions of the Creative Commons Attribution (CC BY) license (https:/ / creativecommons.org/licenses/by/ $4.0 /)$.

\begin{abstract}
To improve the measurement and subsequent use of human skin temperature $\left(T_{\mathrm{sk}}\right)$ data, there is a need for practical methods to compare $T_{\mathrm{sk}}$ sensors and to quantify and better understand measurement error. We sought to develop, evaluate, and utilize a skin model with skin-like thermal properties as a tool for benchtop $T_{\text {sk }}$ sensor comparisons and assessments of local temperature disturbance and sensor bias over a range of surface temperatures. Inter-sensor comparisons performed on the model were compared to measurements performed in vivo, where 14 adult males completed an experimental session involving rest and cycling exercise. Three types of $T_{\text {sk }}$ sensors (two of them commercially available and one custom made) were investigated. Skin-model-derived inter-sensor differences were similar (within $\pm 0.4{ }^{\circ} \mathrm{C}$ ) to the human trial when comparing the two commercial $T_{\text {sk }}$ sensors, but not for the custom $T_{\text {sk }}$ sensor. Using the skin model, all surface $T_{\text {sk }}$ sensors caused a local temperature disturbance with the magnitude and direction dependent upon the sensor and attachment and linearly related to the surface-to-environment temperature gradient. Likewise, surface $T_{\mathrm{sk}}$ sensors also showed bias from both the underlying disturbed surface temperature and that same surface in its otherwise undisturbed state. This work supports the development and use of increasingly realistic benchtop skin models for practical $T_{\mathrm{sk}}$ sensor comparisons and for identifying potential measurement errors, both of which are important for future $T_{\text {sk }}$ sensor design, characterization, correction, and end use.
\end{abstract}

Keywords: human skin temperature; thermometry; temperature sensor; measurement bias; measurement error; skin model; thermal strain

\section{Introduction}

There is enduring and wide-ranging interest in human skin temperature $\left(T_{\mathrm{sk}}\right)$, spanning classic physiology research [1,2], general assessment of thermal strain [3], and emerging health monitoring applications $[4,5]$. Reasons for such interest include the importance of the skin in maintaining thermal homeostasis [6] and the way in which the skin-as the body's external interface-offers potential insight into other physiological or psychophysical responses or parameters (e.g., [7,8]). While the skin is typically an easily accessible site for measurement, this ease of measurement may belie certain challenges involved in accurately quantifying human $T_{\mathrm{sk}}$. Indeed, the method used to measure $T_{\mathrm{sk}}$ can influence the measured outcome $[9,10]$. With increasing interest in wearable technologies (coupled with the ease of adding temperature sensors to multi-parameter measurement systems) and the associated potential for large and personalized datasets, understanding limitations of measurement techniques is necessary to maximize the validity of data use. 
Challenges involved in the accurate measurement of human $T_{\text {sk }}$ were the focus of reasonable attention during the first half of the 20th century, with bare-wire thermocouples and radiometers commonly constructed and studied (e.g., [11-13]). From this early body of work, indications were that, at least under resting conditions, carefully designed radiometers (non-contact method) provided the best estimate of the 'true' $T_{\text {sk }}[11,14,15]$. Bare-wire thermocouples, consisting of fine wires with diameters less than $0.6 \mathrm{~mm}$, in direct contact with the skin compared well with radiometers (often within $\pm 0.5{ }^{\circ} \mathrm{C}$ of the radiometer), with the magnitude of the difference in each case better or worse depending upon variables such as the thermocouple diameter, coverage or method of attachment, applied pressure, and environmental conditions [16,17]. A relatively detailed understanding was developed for the sensors and measurement purposes of the time. However, these delicate thermocouples were, like the radiometer, not practical for meeting general modern demands for measuring human $T_{\text {sk }}$, particularly during physical activity or under clothing and other equipment or body coverings.

There has been greater availability of commercially made, more convenient, and more robust contact temperature sensors over the late 20th and early 21st centuries. Practical advantages of being able to affix such sensors directly to the skin surface likely contributed to the widespread adoption of the contact method of measurement. However, measurement limitations of these contemporary (and comparatively bulkier) $T_{\text {sk }}$ sensors are incompletely characterized. Interrelated challenges include that the measurement system may modify the local $T_{\text {sk }}$ via effects on heat and mass transfer [18] and that the sensor is in contact with other mediums, such as the ambient environment and attachments (e.g., tape), in addition to the skin itself [19-22]. The interplay between the physical properties of a sensor system, the skin, and the measurement conditions may contribute to the mixed agreement between sensor systems reported in more recent studies [21,23-26]. Local modifications of human $T_{\text {sk }}$ have been demonstrated by obstructing evaporative heat transfer (in vivo $[27,28]$ ) and by insulating the $T_{\text {sk }}$ sensor (numerical simulation [18]). However, a detailed practical assessment of both systematic error (bias) and local $T_{\text {sk }}$ modification under the same measurement conditions is lacking. To this end, laboratory tools that facilitate investigation of measurement error under conditions that approximate end use are warranted, given the impracticality and logistical constraints of using human skin in vivo. Similarly, laboratory tools that facilitate relatively easy and 'standardized' intra- or inter-sensor comparisons are required, given the proliferation of monitoring technologies and associated sensor designs and the emerging need for investigating or tracking relative measurement performance within or among those sensors. Laboratory models with metallic surfaces have been used in the past [21,22,29-31], typically to capitalize on heat transfer within the material itself, although models that more realistically reflect the thermal properties of human skin would be advantageous.

Here, we sought to develop, evaluate, and utilize a synthetic skin model with realistic thermal properties as a tool for benchtop $T_{\text {sk }}$ sensor comparisons and assessments of measurement error. Following production of the thermal skin model, our aim was to (1) evaluate the suitability of this skin model as a practical substitute to human skin for inter-sensor comparisons of contact $T_{\mathrm{sk}}$ sensors. This evaluation was performed by using three types of contact $T_{\text {sk }}$ sensors and comparing model-derived inter-sensor differences to the corresponding inter-sensor differences determined on human skin in vivo during rest and cycling exercise. Next, utilizing small reference temperature sensors embedded within the skin model, we sought to better understand potential measurement errors and other local temperature effects of using contact $T_{\text {sk }}$ sensors. Thus, the interrelated second and third aims were to (2) characterize the magnitude of local temperature disturbances at the model surface caused by the presence of selected $T_{\text {sk }}$ sensors and an attachment tape and (3) characterize the magnitude of measurement bias when using selected $T_{\text {sk }}$ sensors. 


\section{Materials and Methods}

\subsection{Orientation}

Following the conceptualization and production of a thermal skin model, this model was used as a platform for detailed $T_{\text {sk }}$ sensor assessment. Model experiments involved two parts: (1) inter-sensor comparisons and (2) characterization of local temperature disturbances sensor bias. A human trial was undertaken for in vivo inter-sensor $T_{\text {sk }}$ comparisons, with the outcome compared to the model inter-sensor comparisons. Because specific outcomes from the human trial were used to inform part of the data analysis in the skin model component, the human trial (Section 2.4) is described below before the skin model experiments (Section 2.5).

\subsection{Production of the Skin Model}

A thermal skin model (outer dimensions $300 \mathrm{~mm} \times 300 \mathrm{~mm} \times 10 \mathrm{~mm}$ ) was made using a dark gray silicone elastomer (polydimethylsiloxane; Sylgard 170; Dow Corning, Midland, MI, USA). Selected properties of this skin simulant were (reported in more detail by Zhai et al. [32]): thermal conductivity $\sim 0.23 \mathrm{~W} /(\mathrm{m} \cdot \mathrm{K})$, thermal diffusivity $\sim 12.8 \times 10^{-8} \mathrm{~m}^{2} \cdot \mathrm{s}^{-1}$, emissivity $\sim 0.9$, and density $\sim 1350 \mathrm{~kg} \cdot \mathrm{m}^{-3}$, which compare quite well with human epidermis: $0.21-0.63 \mathrm{~W} /(\mathrm{m} \cdot \mathrm{K}), 4.9-14.6 \times 10^{-8} \mathrm{~m}^{2} \cdot \mathrm{s}^{-1}, 0.96-0.99$, and $\sim 1200 \mathrm{~kg} \cdot \mathrm{m}^{-3}$ for the same properties, respectively.

The silicone elastomer was prepared from the precursors (Sylgard 170A/170B) at a ratio of $1: 1$ by mass, mixed, then de-gassed in a vacuum chamber at ambient lab temperature; the mix was carefully poured into a mold and cured under ambient lab conditions $\left(22.8 \pm 0.6{ }^{\circ} \mathrm{C}, 63 \pm 3 \%\right.$ relative humidity; $\left.\mathrm{RH}\right)$. Small glass bead thermistors (bead diameter $0.8 \mathrm{~mm}$; type B57540G1, $10 \mathrm{k} \Omega$; Epcos AG, Munich, Germany) were embedded in the skin simulant, with the primary sensor-that was used as the surrogate of the model surface temperature (reference temperature; $T_{\text {ref }}$ )—being directly subsurface (within $1 \mathrm{~mm}$ of the surface). Being directly subsurface facilitated the measurement of $T_{\text {ref }}$ with coverage by a surface $T_{\text {sk }}$ sensor and/or attachment (disturbed $T_{\text {ref }}\left(T_{\mathrm{d}}\right)$ ) and without any coverage (undisturbed $T_{\text {ref }}\left(T_{\mathrm{u}}\right)$ ). A schematic is given in Figure 1, and more detail about the model setup is provided in Appendix A, including the selection of $T_{\mathrm{u}}$. Thermistors were used in the skin model because of their high sensitivity to changes in temperature within the narrow temperature range physiologically relevant for humans.

The thermistors embedded in the skin simulant were calibrated in situ using a calibration chamber (OptiCal; Michell Instruments Ltd., Cambridge, UK) and an externally calibrated precision laboratory Pt100 sensor and thermometer as the reference measurement (Kelvimat 4323; Burster GmbH, Gernsbach, Germany; resolution $0.01{ }^{\circ} \mathrm{C}$, uncertainty $0.02{ }^{\circ} \mathrm{C}$; recorded at $5 \mathrm{~s}$ intervals). Data from the embedded thermistors were recorded at $10 \mathrm{~s}$ intervals with a resolution of $\leq 0.01{ }^{\circ} \mathrm{C}$ using a data logger (Squirrel SQ2020-2F8; Grant Instruments Ltd., Cambridge, UK). The calibration procedure covered the temperature range of $15-40^{\circ} \mathrm{C}$ with stepped-intervals of $\sim 5^{\circ} \mathrm{C}$ and $\geq 80$ min duration per step. Eight-minute steady states were identified where the steady state standard deviation (SD) was $<0.007^{\circ} \mathrm{C}$ for the reference, and mean data over these eight-minute periods were used to generate sensor-specific corrections using linear least-squares regression (Appendix B).

Temperature control of the skin model was achieved using an aluminum plate immediately below the skin simulant; the aluminum plate had internal channels, which were perfused using a $25 \mathrm{~L}$ water bath and circulation thermostat (RM 25 S; Lauda GmbH \& Co. KG, Lauda-Königshofen, Germany). The setup was capable of a steady state stability of $\mathrm{SD}<0.01{ }^{\circ} \mathrm{C}$ [22]. 


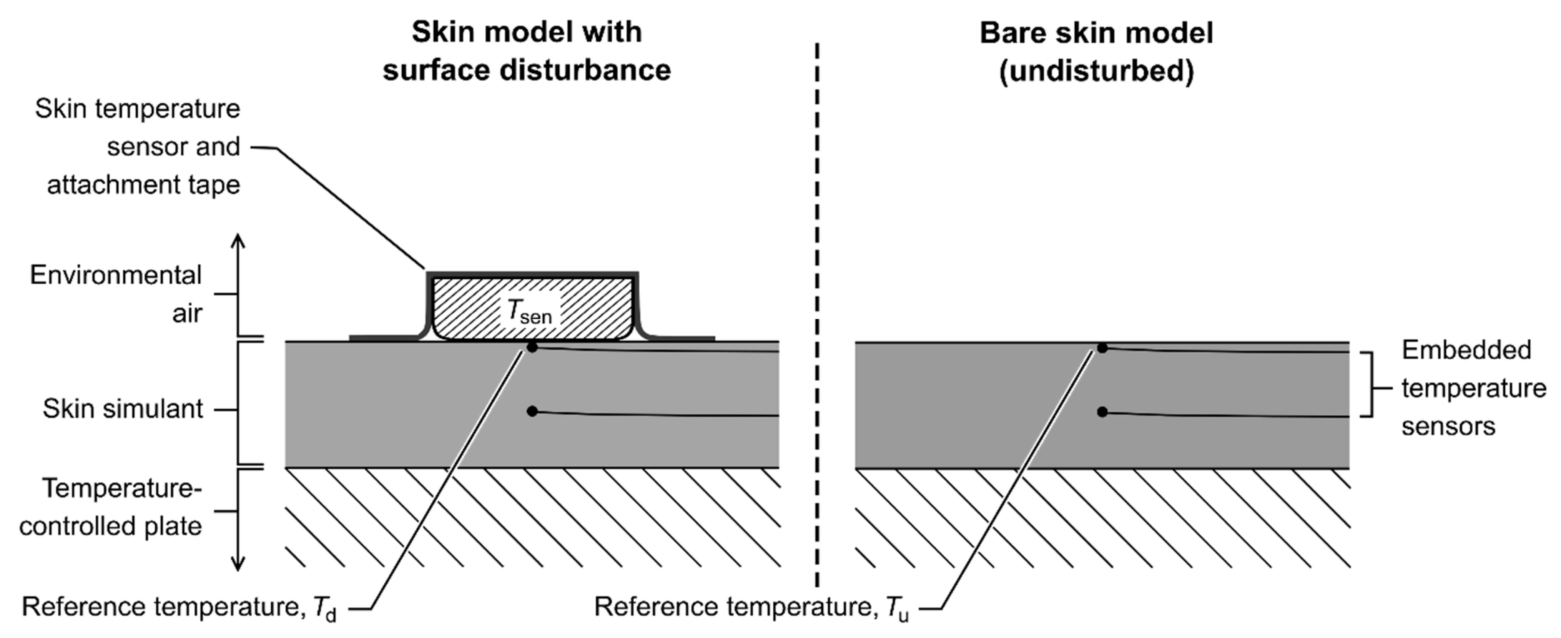

Figure 1. Cross-section of the skin model at the measurement site, showing the surface position of the skin temperature sensor and/or tape when used (left) and the same section of the model in the state 'unmeasured' by the skin temperature sensor (right). The top embedded temperature sensor (directly subsurface) was used as the reference surface temperature, becoming the disturbed reference temperature $\left(T_{\mathrm{d}}\right)$ when a surface skin temperature sensor was present (left) and the undisturbed reference temperature $\left(T_{\mathrm{u}}\right)$ when the model surface was bare (right). This setup enabled characterization of the relationships among the temperature of the surface skin temperature sensor $\left(T_{\mathrm{sen}}\right), T_{\mathrm{d}}$, and the corresponding $T_{\mathrm{u}}$ under otherwise equivalent conditions.

\subsection{Skin Temperature Sensors and Attachment Tape}

Three types of $T_{\mathrm{sk}}$ sensors were used throughout this work (Figure 2):

- Maxim iButtons (DS1922L, Maxim Integrated Inc., San Jose, CA, USA). The surface of the iButton with a rounded edge was used as the contact surface [23].

- Grant thermistors (EUS-U-VS5-0, Grant Instruments Ltd., Cambridge, UK).

- Custom thermistors, each consisting of a glass-encapsulated NTC thermistor (type B57550G1, $10 \mathrm{k} \Omega$; diameter $1.3 \mathrm{~mm}$; Epcos AG, Germany) set inside a small volume of silicone elastomer encapsulant (Sylgard 170; Dow Corning, Midland, MI, USA).

The iButtons and Grant thermistors were selected based on being two of the most common commercial sensors used for measuring human $T_{\mathrm{sk}}$ in published studies involving exercise and other physical activity over the period 2011-2016 [10]. The custom thermistors were used as a model for investigating the idea of having thermal properties of the $T_{\mathrm{sk}}$ sensor matching the medium it is measuring (the silicone elastomer used to encapsulate the thermistor in the custom sensor was the same silicone elastomer used to make the skin simulant; Section 2.2).

All data from $T_{\mathrm{sk}}$ sensors were recorded at $10 \mathrm{~s}$ intervals for sensor calibration and during experimental sessions. Data from the custom thermistors and Grant thermistors were collected with a resolution of $\leq 0.01^{\circ} \mathrm{C}$ using a data logger (Squirrel SQ2020-2F8). Data from the iButtons were self-logged with a resolution of $0.0625^{\circ} \mathrm{C} . T_{\text {sk }}$ sensors were calibrated prior to each set of experimental sessions (skin model and human trial) using the calibration chamber, Pt100 sensor and thermometer, and procedure as described for the thermistors embedded in the skin simulant (Section 2.2 and Appendix B). During each calibration run, $T_{\mathrm{sk}}$ sensors were arranged spatially to ensure they avoided contact with each other and the chamber walls.

For both sets of experiments (skin model and human trial), a single layer of porous medical tape was used to attach the $T_{\mathrm{sk}}$ sensors $\left(\right.$ Hypafix $\left.^{\circledR}, 16002\right)$. The tape was white, non-woven polyester with acrylic adhesive (thickness, $0.25 \pm 0.03 \mathrm{~mm}$; mass-per-unit area, $76 \pm 1 \mathrm{~g} \cdot \mathrm{m}^{-2}$; BSN Medical GmbH, Hamburg, Germany). The tape size used was $35 \mathrm{~mm} \times 50 \mathrm{~mm}$ for the iButton and $30 \mathrm{~mm} \times 50 \mathrm{~mm}$ for the Grant and custom thermistors, keeping the total surface area of the measured surface (skin or model) covered approximately the same irrespective of the sensor used. 


\section{Skin temperature sensors}

Shown (left to right) as bottom, side, and top elevation
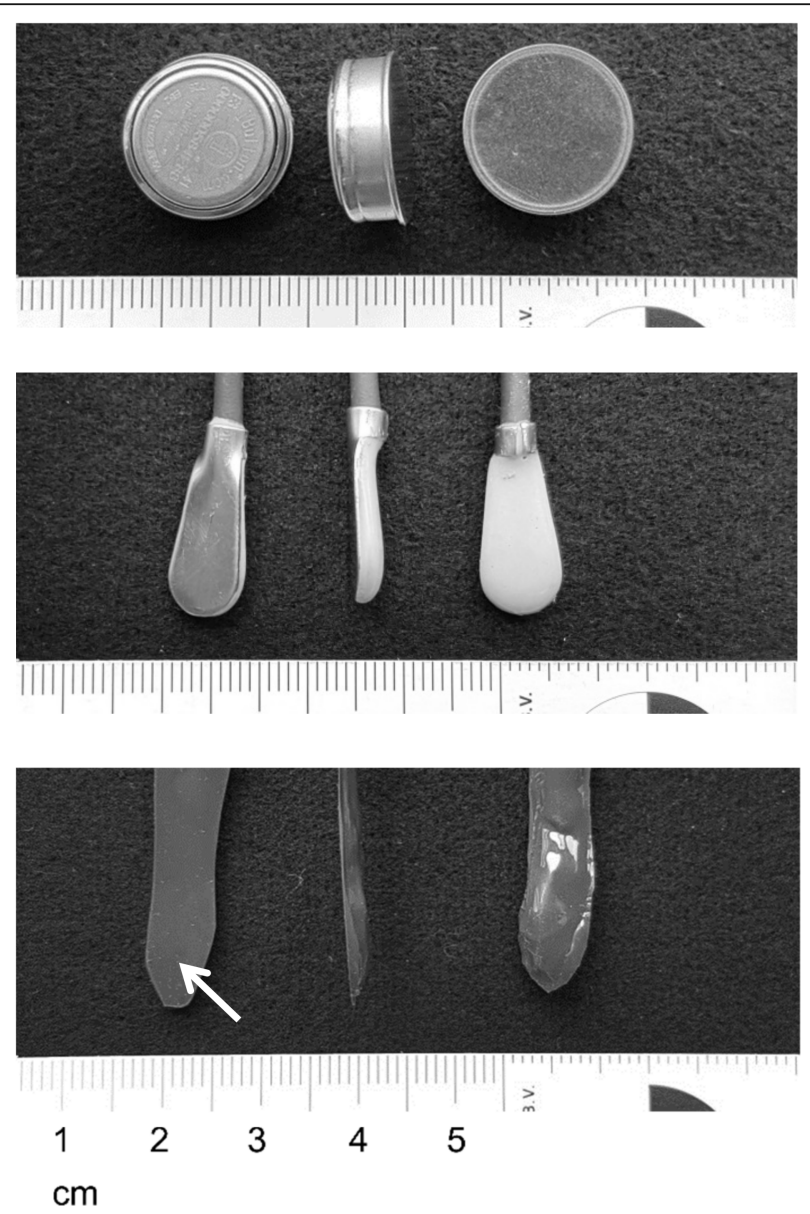

\section{Selected information}

iButtons (Maxim Integrated Inc., USA); wireless.

Sensing component inside stainless steel can.

Manufacturer-reported 'accuracy' $\pm 0.5^{\circ} \mathrm{C}$ over the range of $-10{ }^{\circ} \mathrm{C}$ to $65^{\circ} \mathrm{C}$.

Grant thermistors (Grant Instruments Ltd., UK); wired. Sensing component mounted on stainless steel base and encapsulated. Manufacturer-reported 'accuracy' $\pm 0.2{ }^{\circ} \mathrm{C}$ over the range of $0{ }^{\circ} \mathrm{C}$ to $70{ }^{\circ} \mathrm{C}$.

Custom thermistors, $1.3 \mathrm{~mm}$ diameter thermistor (Epcos AG, Germany) encapsulated in silicone elastomer (Sylgard 170; Dow Corning, USA); wired. White arrow indicates approximate location of the thermistor head ( $<1 \mathrm{~mm}$ from bottom surface). Excess silicone elastomer away from the sensor head was for protecting lead wires and anchoring the skin attachment (tape).

Figure 2. Skin temperature sensors and selected information.

\subsection{Human Trial-In Vivo Skin Temperature Sensor Comparison}

\subsubsection{Participants}

Fourteen male adults participated in the human trial (mean $\pm \mathrm{SD}$; age, $28.1 \pm 3.4 \mathrm{y}$; mass, $79.0 \pm 5.1 \mathrm{~kg}$; standing height, $1.84 \pm 0.05 \mathrm{~m}$ ). All participants were non-smokers, apparently healthy, and exercised habitually (typically $\geq 3$ sessions/week exceeding $45 \mathrm{~min} / \mathrm{session}$ ). Written informed consent was obtained from all participants. The ethics committee of Eastern Switzerland (Project ID: 2017-01376, EKOS 17/129) approved the study, and all procedures performed were in accordance with the ethics committee and with the 1964 Declaration of Helsinki and its later amendments.

\subsubsection{Procedures}

There was one experimental session per participant (Figure 3). Participants were requested to abstain from alcohol and caffeine within $12 \mathrm{~h}$ of the trial, strenuous exercise within $48 \mathrm{~h}$ of the trial, and to have a light meal $\sim 1 \mathrm{~h}$ before reporting to the laboratory at $0800(n=11)$ or $1400 \mathrm{~h}(\mathrm{n}=3)$. Experiments were completed in an environmental chamber for controlled environmental conditions (temperate conditions, targeting $24{ }^{\circ} \mathrm{C}$ and $50 \% \mathrm{RH}$; actual measured conditions across experimental sessions were $23.6 \pm 0.3^{\circ} \mathrm{C}$, $46 \pm 3 \% \mathrm{RH})$. Air velocity of $\sim 0.5 \mathrm{~m} \cdot \mathrm{s}^{-1}$ during seated rest and $\sim 1 \mathrm{~m} \cdot \mathrm{s}^{-1}$ during exercise was provided by two vertically aligned $0.25 \mathrm{~m}$ diameter fans, with those fans $2.3 \mathrm{~m}$ and $1.65 \mathrm{~m}$ in front of the participant during rest and exercise, respectively. Rest comprised 
sitting on an office chair, and exercise consisted of cycling on a stationary ergometer (cyclus 2; RBM elektronik-automation GmbH, Leipzig, Germany). Exercise was moderate intensity for the first $30 \mathrm{~min}$ ( $15 \mathrm{~min}$ at fixed-load of $1.7 \mathrm{~W} \cdot \mathrm{kg}^{-1}$ body mass (FL1), $15 \mathrm{~min}$ at $2.0 \mathrm{~W} \cdot \mathrm{kg}^{-1}$ (FL2)) followed by a $15 \mathrm{~min}$ light-intensity warm down $\left(1.0 \mathrm{~W} \cdot \mathrm{kg}^{-1}\right.$; FL3). Pedaling cadence was $75 \pm 3 \mathrm{rpm}$ throughout.

Participants wore their own sport shoes, socks, and running shorts and an experimentersupplied standardized short-sleeve $100 \%$ cotton t-shirt (olive green) in the appropriate generic size (small, medium, or large; garment ease, and therefore fit, was not otherwise characterized). The t-shirt fabric was conditioned and characterized at $20 \pm 2{ }^{\circ} \mathrm{C}$ and $65 \pm 4 \% \mathrm{RH}$ [33] in accordance with the corresponding standard test method: thickness [34], $0.83 \pm 0.02 \mathrm{~mm}$; mass per unit area [35], $189 \pm 4 \mathrm{~g} \cdot \mathrm{m}^{-2}$; air permeability [36], $733 \pm 19 \mathrm{~L} /\left(\mathrm{m}^{2} \cdot \mathrm{s}\right)$; and thermal resistance [37], $0.030 \pm 0.001 \mathrm{~m}^{2} \cdot \mathrm{K} / \mathrm{W}$.

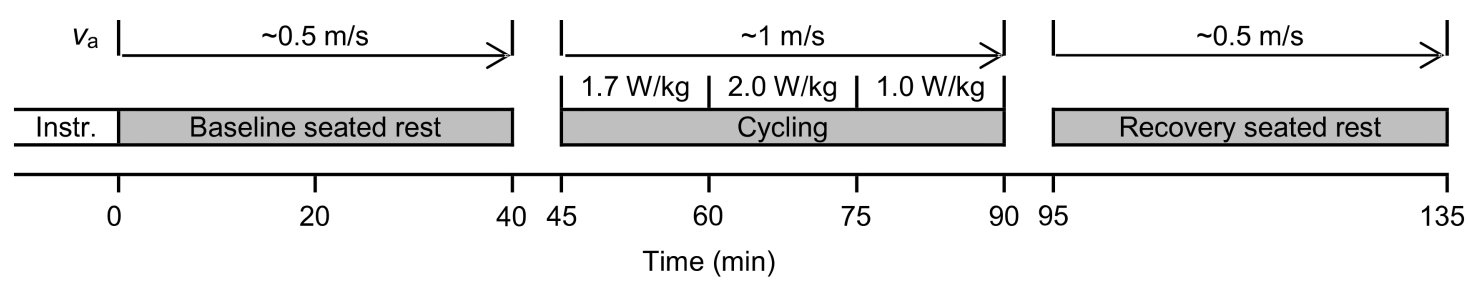

Figure 3. Schematic of the human trial experimental protocol. Minutes 40-45 and 90-95 were used for transitioning between the chair and cycle ergometer and to check for sensor or attachment issues. Intsr., instrumentation; $v_{\mathrm{a}}$, air velocity.

\subsubsection{Experimental Measurements}

Participants were instrumented in the test environment. The $T_{\mathrm{sk}}$ (three sensor types; Figure 2), and RH at the skin surface were each measured on the left side of the body at four sites [38]: upper chest (pectoralis major), lateral arm (at widest circumference), anterior thigh (midway along the femur), and anterior leg (muscle belly of tibialis anterior). $\mathrm{RH}$ at the skin surface, and the corresponding temperature (for subsequent calculation of absolute vapor pressure), were measured at $10 \mathrm{~s}$ intervals using an integrated hygrometer and thermistor (SHT15 sensor and MSR12 logger; MSR GmbH, Seuzach, Switzerland), which had been calibrated over the range of $40-87.5 \% \mathrm{RH}$ and $15-40^{\circ} \mathrm{C}$ (OptiCal calibration chamber) within two months of commencing the study.

The measurement sites were cleaned with an isopropyl swab and lightly shaven $\sim 30 \mathrm{~min}$ before instrumentation. For the relative position of the three $T_{\mathrm{sk}}$ sensors at each body site, a $50 \mathrm{~mm} \times 50 \mathrm{~mm}$ square was marked on the skin then separated into four equal quadrants, $25 \mathrm{~mm} \times 25 \mathrm{~mm}$ each, with each sensor then randomly allocated to a quadrant [25]. (A sensor used to measure next-to-skin microclimate air temperature was allocated to the remaining quadrant; this measurement was practically challenging in the context of body movement, and, due to insufficient confidence in the consistency of the sensor distance from the skin surface, the microclimate temperature data are not reported here.) The $\mathrm{RH}$ sensor at each body site was always positioned $\sim 25 \mathrm{~mm}$ superior to the square described. The sensors at the chest were covered in all trials, whereas the sensors at the arm, thigh, and leg were always uncovered (the t-shirt left arm had been cropped accordingly). Sensors were affixed to the skin using a single layer of medical tape (described in Section 2.3).

Heart rate was recorded at $5 \mathrm{~s}$ intervals (S810i HR monitor; Polar, Kempele, Finland). Near-nude mass (including underwear) was measured immediately before and after entering and exiting the environmental chamber (ID5 Multi range; Mettler Toledo, Columbus, $\mathrm{OH}$, Switzerland). 


\subsubsection{Calculations}

Weighted-mean $T_{\mathrm{sk}}\left({ }^{\circ} \mathrm{C}\right)$ was calculated for each $T_{\mathrm{sk}}$ sensor type using the four measurement sites (Section 2.4.3) as [38]:

$$
\text { Weighted-mean } T_{\mathrm{sk}}=0.3 \cdot T_{\text {chest }}+0.3 \cdot T_{\mathrm{arm}}+0.2 \cdot T_{\text {thigh }}+0.2 \cdot T_{\text {leg }}
$$

Period means ( $3 \mathrm{~min}$ ) were then used for subsequent sensor comparisons: end of baseline rest (mins 36-39 from start of trial), end of each block of fixed-load cycling (mins 57-60, 72-75, and 87-90), and midway through and end of recovery rest (mins 112-115 and 131-134). The $3 \mathrm{~min}$ period immediately preceding the onset of sweating was also used, with the timing being specific for each participant. The within-participant, inter-sensor differences were calculated (Grant-custom; iButton-custom; iButton-Grant) and summarized as group-mean differences with corresponding $95 \%$ confidence intervals (CI). CI were calculated using the standard error of the difference and the corresponding critical value from the $t$-distribution; CI were unadjusted [39].

$\mathrm{RH}$ and corresponding temperature data were used to calculate absolute vapor pressure $(\mathrm{kPa})$ in accordance with formulae given elsewhere [40]. The onset of sweating was estimated by identifying a distinct increase in the absolute vapor pressure $(>0.5 \mathrm{kPa})$ after the beginning of exercise [28]. 'Continuous' data (10 s intervals) of absolute vapor pressure from the four body sites were assessed, and the earliest of the four sites was taken as the onset of sweating.

\subsection{Thermal Skin Model Experiments}

\subsubsection{Procedures}

Experiments were performed in an environmental chamber at $23.8 \pm 0.1{ }^{\circ} \mathrm{C}$ and $42 \pm 2 \% \mathrm{RH}$ throughout (radiant temperature $\cong$ air temperature), closely matching the environmental temperature and humidity used for the human trial (means within $0.2{ }^{\circ} \mathrm{C}$ and $4 \% \mathrm{RH}$ ). There were two air velocity conditions: $\sim 0.5 \mathrm{~m} \cdot \mathrm{s}^{-1}$ (with enclosure and fans) and $\sim 0.2 \mathrm{~m} \cdot \mathrm{s}^{-1}$ (ambient air movement inside the environmental chamber; Appendix A).

An experimental run consisted of measurements during stepwise increases in the temperature of the skin model (five temperature steps at $30 \mathrm{~min}$ per step). The steps were set up such that the surface temperature of the skin model began at approximately the same temperature as the environmental air temperature (i.e., $\sim 0^{\circ} \mathrm{C}$ gradient from surface to environment $)$ and finished at $\sim 40{ }^{\circ} \mathrm{C}\left(0.5 \mathrm{~m} \cdot \mathrm{s}^{-1}\right.$ condition; temperature gradient range of $\left.\sim 0-16{ }^{\circ} \mathrm{C}\right)$ or $\sim 42{ }^{\circ} \mathrm{C}\left(0.2 \mathrm{~m} \cdot \mathrm{s}^{-1}\right.$ condition; temperature gradient range of $\left.\sim 0-18{ }^{\circ} \mathrm{C}\right)$; the difference in the temperature range between air velocity conditions was due to the greater heat flux through the skin model with the higher air velocity for a given supply temperature of the underlying aluminum plate.

There were six surface-coverage conditions, corresponding to the sensor and/or attachment configuration used at the model surface directly above the model $T_{\text {ref }}$ sensor: (1) custom thermistor and tape, (2) Grant thermistor and tape, (3) iButton and tape, (4) iButton only (i.e., without fixation), (5) tape only, and (6) no covering (bare model surface). The tape used to attach the $T_{\mathrm{sk}}$ sensors was as described in Section 2.3; for the 'tape only' condition, the tape dimensions were $25 \mathrm{~mm} \times 50 \mathrm{~mm}$ to keep consistent the area of the skin model surface covered. The iButton was used to investigate the effect of the attachment tape (sensor covered with tape versus sensor without tape coverage), because this sensor, being wireless, was able to rest on the model surface under its own weight. The bare surface condition, with no $T_{\text {sk }}$ sensor or tape, was used to establish the reference $T_{\mathfrak{u}}$ (see Appendix A.2 for more detail).

Each of the six surface-coverage conditions (with $n=5$ distinct replicates for each) was repeated under each air velocity condition, giving $60(6 \times 5 \times 2)$ experimental runs. Testing was performed in blocks split by air velocity condition, with the sequence within each block ordered by replicate and randomized by coverage condition (i.e., all coverage conditions for replicate 1 were completed before moving on to replicate 2 , and so on). 


\subsubsection{Calculation of Steady State Data}

Steady state means for temperature data were calculated over minutes 21-29 (of 30) within each step of each run, giving paired $X-Y$ data $\left(T_{\mathrm{sk}}\right.$ sensor and $T_{\text {ref, }}$, respectively) for runs in which $T_{\mathrm{sk}}$ sensors were also used. All steady states were confirmed by a within-sensor SD of $<0.05^{\circ} \mathrm{C}$. The $T_{\text {ref }}$ data $\left(T_{\mathrm{d}}\right.$ and $\left.T_{\mathrm{u}}\right)$ were then corrected to account for the $T_{\text {ref }}$ sensor being subsurface (within the first $1 \mathrm{~mm}$ of the skin model), rather than at the surface, itself. Assuming an approximate linear temperature gradient, these location errors were estimated for each steady state in each individual run using Fourier's Law and the corresponding data from the embedded sensor at a second depth (Figure 1). The magnitudes of these estimated location errors over all experimental runs were $0.00-0.39^{\circ} \mathrm{C}$. (The $T_{\text {sk }}$ sensor data were not corrected in this way, consistent with normal use.)

\subsubsection{Comparison of Thermal Skin Model with Human Trial}

The suitability of the skin model was explored by comparing the model-derived mean differences among the three $T_{\mathrm{sk}}$ sensors to those obtained in vivo from the human trial. Because the absolute temperature of the surface being measured (i.e., skin model or human skin) would itself influence the magnitude of the respective inter-sensor differences, intersensor comparisons from the skin model needed to be calculated at surface temperatures that corresponded to the surface (i.e., skin) temperatures in the human trial. Therefore, linear regression was used to estimate the $T_{\mathrm{sk}}$ sensor values for a model surface temperature that approximately matched each period mean $T_{\mathrm{sk}}$ from the human trial (an example to supplement the following description is given in Appendix $C$ ).

The relationship between each individual $T_{\text {sk }}$ sensor and the model reference temperature under each air velocity condition were first determined using simple linear regression (ordinary least squares) as:

$$
Y^{\prime}=b_{0}+b_{1} \cdot X
$$

where $Y^{\prime}$ is the estimate of model reference temperature $\left(T_{\mathrm{u}} ;{ }^{\circ} \mathrm{C}\right), b_{0}$ is the intercept $\left({ }^{\circ} \mathrm{C}\right), b_{1}$ is the slope coefficient, and $X$ is the $T_{\mathrm{sk}}$ sensor temperature $\left({ }^{\circ} \mathrm{C}\right)$. All $X-Y$ data were suitable for linear characterization: for each equation produced, the coefficient of determination $\left(R^{2}\right)$ was $>0.99$, and the typical error of the estimates (mean residual error from the fitted regression line) was $<0.01-0.05{ }^{\circ} \mathrm{C}$.

The custom thermistors were used to establish the model-equivalent temperature approximating each period mean from the human trial (Section 2.4.4), because these were the $T_{\mathrm{sk}}$ sensors found to have the least bias (versus $T_{\mathrm{u}}$ ) of the three $T_{\mathrm{sk}}$ sensor types during measurements of the skin model. Accordingly, Equation (2) was used to determine seven model $T_{\mathrm{u}}$ estimates $\left(Y^{\prime}{ }_{1-7}\right)$ approximating each of the seven human trial data summary periods, using the custom thermistor group-mean temperatures from the human trial. Next, Equation (2) was rearranged as:

$$
X^{\prime}=\left(Y^{\prime}-b_{0}\right) / b_{1}
$$

where $X^{\prime}$ is the $T_{\text {sk }}$ sensor temperature estimate $\left({ }^{\circ} \mathrm{C}\right)$. For each individual $T_{\mathrm{sk}}$ sensor within each $T_{\text {sk }}$ type, and for each air velocity condition, $X^{\prime}$ was calculated at each of the seven model $T_{\mathrm{u}}$ estimates corresponding to the human trial $\left(Y_{1-7}^{\prime}\right.$ from above). This process gave temperature estimates for the three $T_{\text {sk }}$ sensor types for 'fixed' model surface temperatures approximating the human trial. Differences $(n=5)$ between the $T_{\mathrm{sk}}$ sensor types were then calculated in the same way as for the human trial (Grant-custom; iButton-custom; iButton-Grant) and summarized as group-mean differences with corresponding 95\% CI. 


\subsubsection{Local Temperature Disturbance and Sensor Bias}

The disturbance of the local skin model temperature $\left({ }^{\circ} \mathrm{C}\right)$ caused by the presence of the surface $T_{\mathrm{sk}}$ sensor and/or attachment was calculated for each steady state within each experimental run (excluding bare surface runs) as:

$$
\text { disturbance }=T_{\mathrm{d}}-T_{\mathrm{u}}
$$

where $T_{\mathrm{d}}$ is the model reference surface temperature when disturbed by the surface $T_{\mathrm{sk}}$ sensor and/or tape attachment $\left({ }^{\circ} \mathrm{C}\right)$, and $T_{\mathrm{u}}$ is the model reference surface temperature for the corresponding steady state in an undisturbed state $\left({ }^{\circ} \mathrm{C}\right)$.

The measurement bias of each surface $T_{\mathrm{sk}}$ sensor was considered here in two forms: difference from the underlying disturbed reference surface temperature (bias from $T_{\mathrm{d}}$ ) and difference from the corresponding undisturbed reference temperature (bias from $T_{\mathrm{u}}$ ). For each $T_{\mathrm{sk}}$ sensor, at each steady state within each applicable experimental run, bias was calculated as:

$$
\text { bias }=T_{\text {sen }}-T_{\text {ref }}
$$

where bias $\left({ }^{\circ} \mathrm{C}\right)$ is either bias from $T_{\mathfrak{u}}$ or bias from $T_{\mathrm{d}}$ (depending on the $T_{\text {ref }}$ used), $T_{\text {sen }}$ is the temperature of the surface $T_{\text {sk }}$ sensor $\left({ }^{\circ} \mathrm{C}\right)$, and $T_{\text {ref }}$ is either $T_{\mathrm{d}}$ or $T_{\mathrm{u}}\left({ }^{\circ} \mathrm{C}\right)$ from the same or corresponding steady state, respectively.

Estimates of local temperature disturbance and sensor bias were summarized as mean and $95 \% \mathrm{CI}$.

\section{Results}

\subsection{Human Trial}

\subsubsection{Heart Rate and Onset of Sweating}

All participants completed the experimental session. The cycling intensity was sufficient to provide moderate cardiovascular strain: heart rate increased from $70 \pm 11$ beats $\cdot \mathrm{min}^{-1}$ at the end of baseline rest to $129 \pm 14$ and $145 \pm 15$ beats. $\min ^{-1}$ at the end of the fixed-load intensities 1 and 2, respectively, then reduced to $121 \pm 14,82 \pm 15$, and $79 \pm 11$ beats. min $^{-1}$ at the end of the warm-down cycling, middle of recovery rest, and end of recovery rest, respectively. The estimated onset of sweating was $7.4 \pm 1.6 \mathrm{~min}$ (range 4.8-10.3 $\mathrm{min}$ ) after the start of cycling. Mass loss over the trial was $0.52 \pm 0.07 \mathrm{~kg}$ with $206 \pm 6 \mathrm{~min}$ between weighing.

\subsubsection{Skin Temperature}

No $T_{\text {sk }}$ sensors were observed to have detached during the trials. One Grant thermistor had a technical issue, causing an offset during the baseline rest period of one experimental session. The data following resolution of the issue was used to estimate the offset and, therefore, estimate the baseline data for that sensor. All original sensors were used throughout the study, and datasets were otherwise complete. Weighted-mean $T_{\text {sk }}$ from the three $T_{\mathrm{sk}}$ sensor types are shown in Figure 4, and the inter-sensor mean differences are shown in Figure 5. For the periods summarized, mean systematic differences between the three $T_{\text {sk }}$ sensor types were always $<0.3{ }^{\circ} \mathrm{C}$ during baseline and recovery rest and $<0.5^{\circ} \mathrm{C}$ during exercise. The largest mean difference was the iButton being $0.45^{\circ} \mathrm{C}$ warmer than the custom thermistor at the end of exercise (Figure 5). 


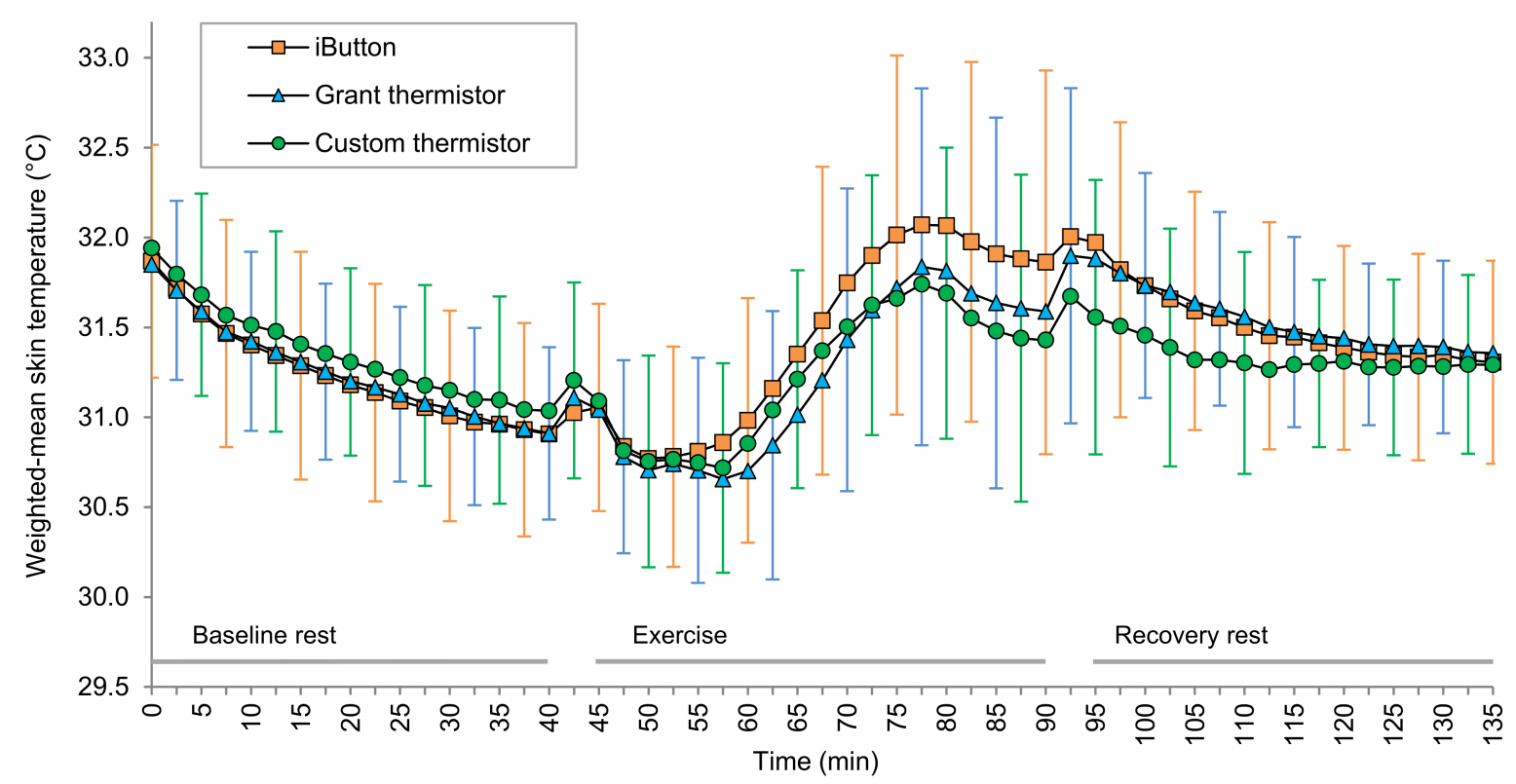

Figure 4. Weighted-mean skin temperature throughout baseline rest, cycling exercise, and recovery rest. Data are group mean $(n=14)$, and error bars indicate the standard deviation. For clarity of display, data are shown at intervals greater than the sampling frequency and the standard deviation for each sensor is shown at alternating time points; orange, blue, and green error bars correspond to iButton, Grant thermistor, and custom thermistor data, respectively.

\subsection{Thermal Skin Model}

In one experimental run, the tape partially detached from the model surface, causing the wired $T_{\mathrm{sk}}$ sensor (Grant thermistor) to partially lift off the model surface; this experimental run was excluded, and a repeat run was performed. There were no other known technical issues with any sensors throughout the experimental runs, and datasets were, therefore, complete.

\subsubsection{Thermal Skin Model Comparison with the Human Trial Data}

Mean differences among the three $T_{\mathrm{sk}}$ sensors are presented in Figure 5, comparing the model-derived values to those from the human trial. Model-derived differences were consistently greater in magnitude than the human trial for comparisons involving custom thermistors (Figure $5 \mathrm{a}, \mathrm{b}$ ). For the comparison of iButtons and Grant thermistors, modelderived mean differences were always within $0.4{ }^{\circ} \mathrm{C}$ of the corresponding mean differences from the human trial (Figure $5 \mathrm{c}$ ). Indeed, for these two $T_{\mathrm{sk}}$ sensors, the model-derived differences with $0.2 \mathrm{~m} \cdot \mathrm{s}^{-1}$ air velocity were particularly close to the human trial for baseline rest, pre-sweating fixed-load cycling, and recovery rest $\left(0.0-0.1^{\circ} \mathrm{C}\right.$ for skin model $0.2 \mathrm{~m} \cdot \mathrm{s}^{-1}$ vs. human trial), and the model-derived differences with $0.5 \mathrm{~m} \cdot \mathrm{s}^{-1}$ air velocity were particularly close for fixed-load cycling after the onset of sweating $\left(<0.1^{\circ} \mathrm{C}\right.$ for skin model $0.5 \mathrm{~m} \cdot \mathrm{s}^{-1} \mathrm{vs}$. human trial).

\subsubsection{Temperature Disturbance}

When the surface of the bare skin model was warmer than the environmental air, the presence of a $T_{\mathrm{sk}}$ sensor and/or attachment caused a local temperature disturbance that increased in magnitude in proportion to the difference between the surface and environmental air temperatures (Figure 6). Coverage with tape only or with the custom thermistor and tape caused the underlying surface (i.e., $T_{\mathrm{d}}$ ) to be warmer than a bare surface under otherwise equivalent conditions (i.e., $T_{\mathrm{u}}$; Figure $6 \mathrm{~b}, \mathrm{~d}$ ), whereas the iButton without tape and the Grant thermistor and tape caused $T_{\mathrm{d}}$ to be cooler than $T_{\mathfrak{u}}$ (Figure $6 \mathrm{c}, \mathrm{e}$ ). For the iButton and tape, the $T_{\mathrm{d}}$ was warmer than the $T_{\mathrm{u}}$ with an air velocity of $0.5 \mathrm{~m} \cdot \mathrm{s}^{-1}$ but lower than $T_{\mathrm{u}}$ with an air velocity of $0.2 \mathrm{~m} \cdot \mathrm{s}^{-1}$ (Figure 6a). The iButton only with an air velocity of $0.5 \mathrm{~m} \cdot \mathrm{s}^{-1}$, caused the greatest disturbance (e.g., $-0.6{ }^{\circ} \mathrm{C}$ at an equivalent to 
$T_{\mathrm{u}}$ of $31^{\circ} \mathrm{C}$ ), while the custom thermistor and tape and tape only each at an air velocity of $0.2 \mathrm{~m} \cdot \mathrm{s}^{-1}$, caused the least disturbance (e.g., both $+0.1^{\circ} \mathrm{C}$ at an equivalent to $T_{\mathrm{u}}$ of $31^{\circ} \mathrm{C}$; Figure 6).
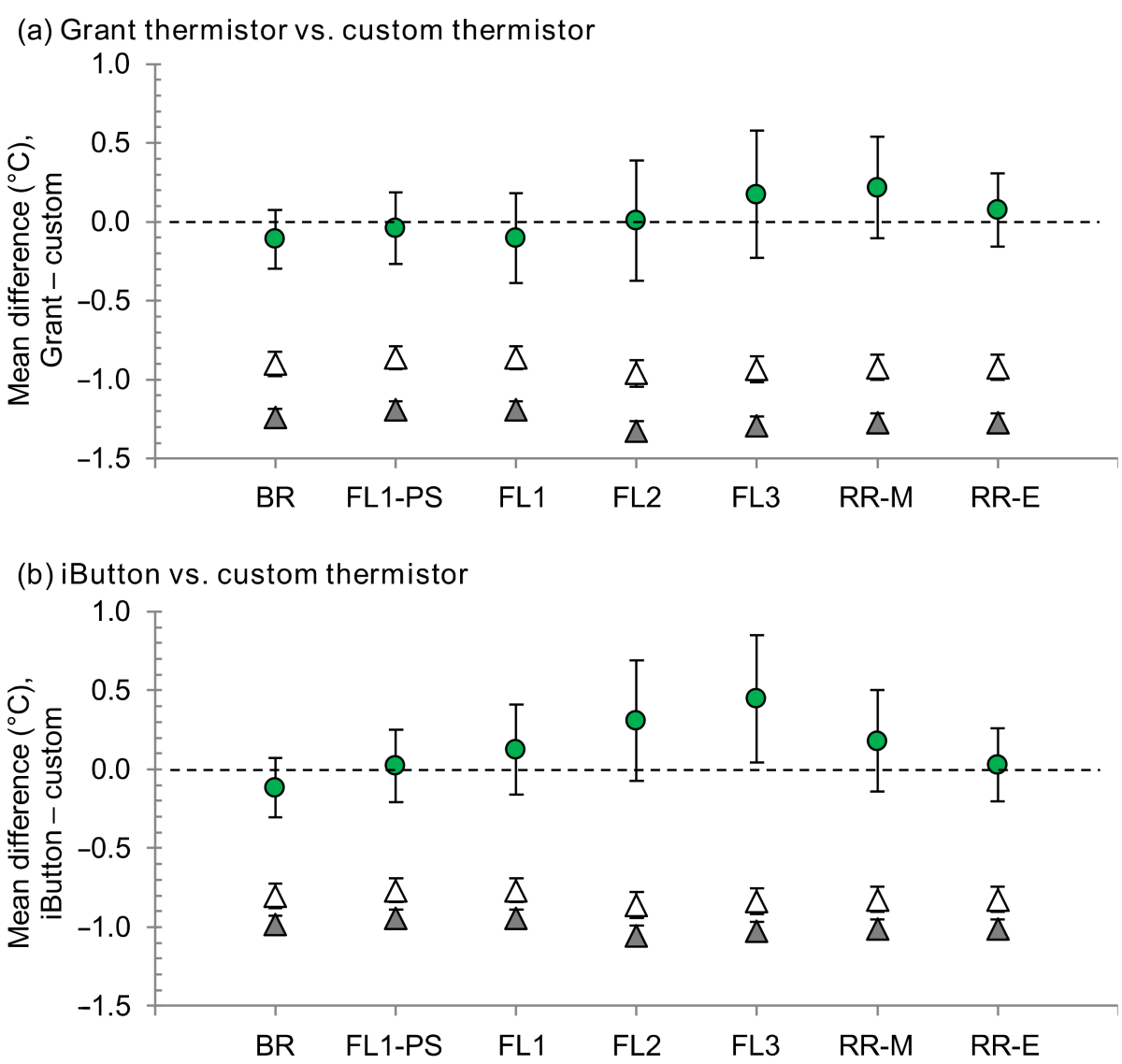

(c) iButton vs. Grant thermistor

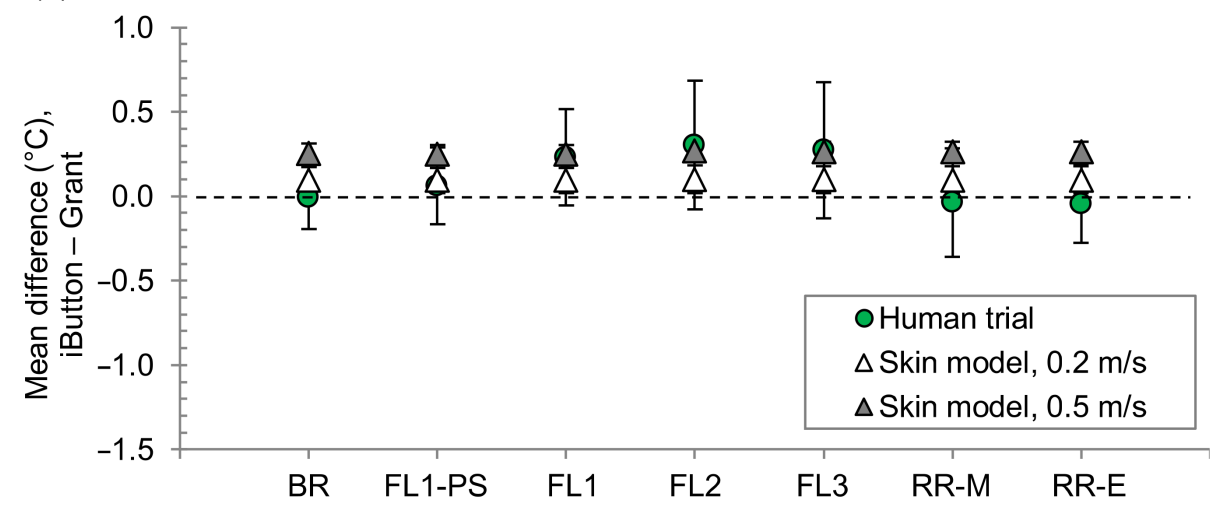

Figure 5. Mean differences between skin temperature sensors $(\mathbf{a}-\mathbf{c})$ during the human trial (weightedmean skin temperature; $\mathrm{n}=14$ ) and skin model experiments (individual sensor temperature; $\mathrm{n}=5$ for each air velocity condition). Error bars indicate $95 \%$ confidence intervals. Negative differences indicate the first sensor listed being cooler than the second sensor listed. BR, end of baseline rest; FL1-PS, fixed-load cycling 1 pre-sweating; FL1-FL3, end of fixed-load cycling 1-3; RR-M, middle of recovery rest; RR-E, end of recovery rest. 


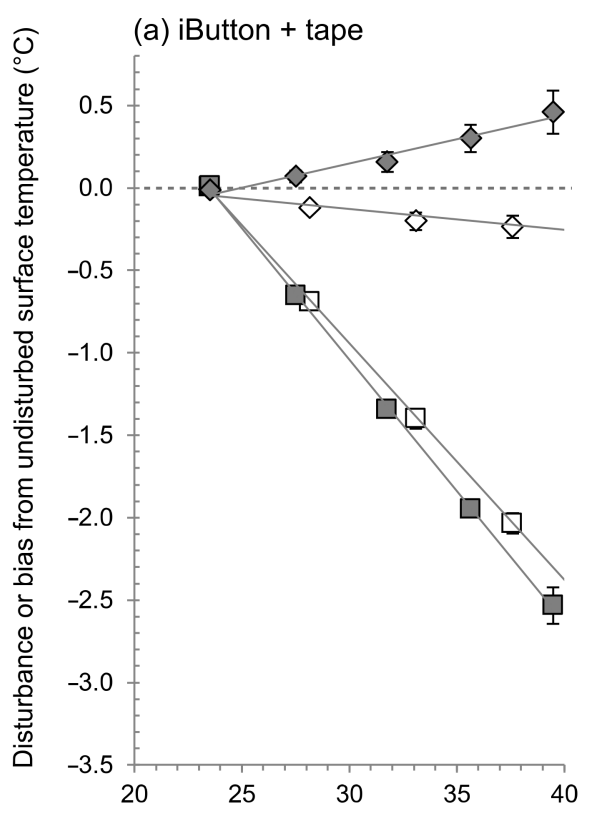

(d) Custom thermistor + tape
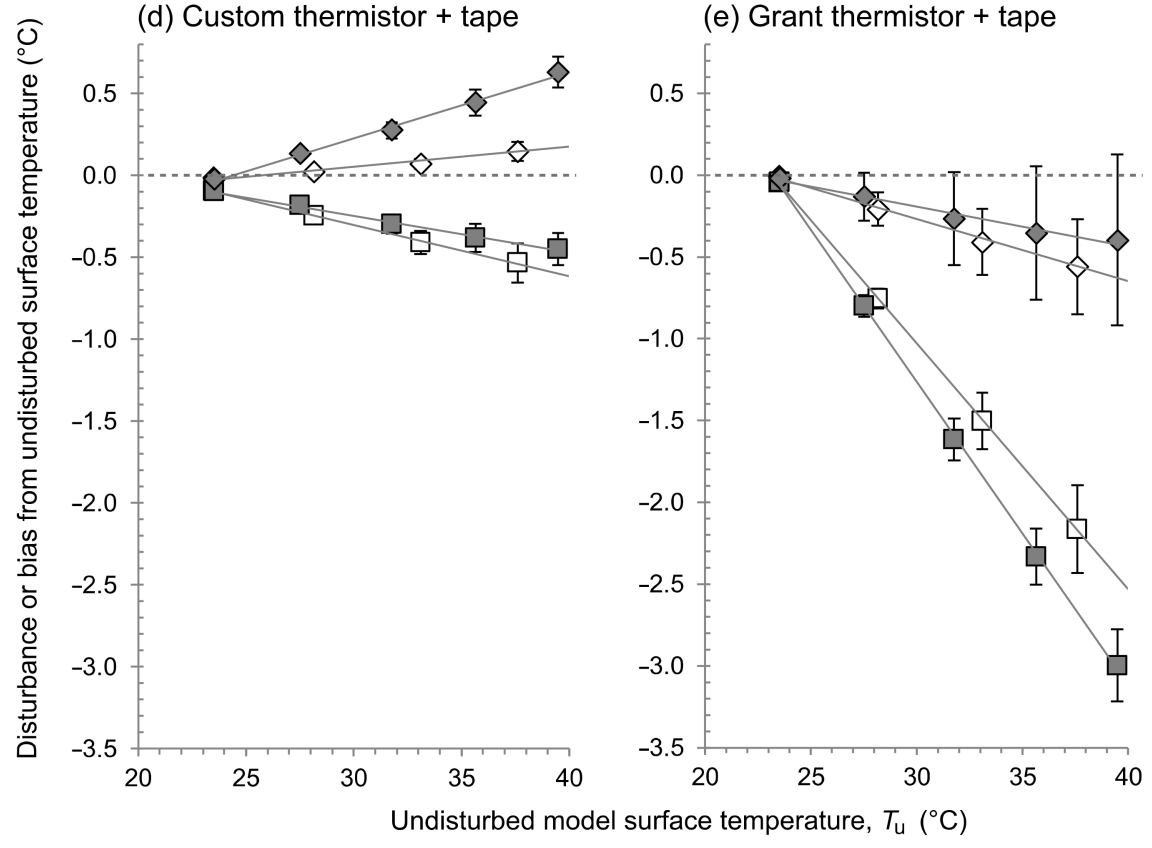

(b) Tape only

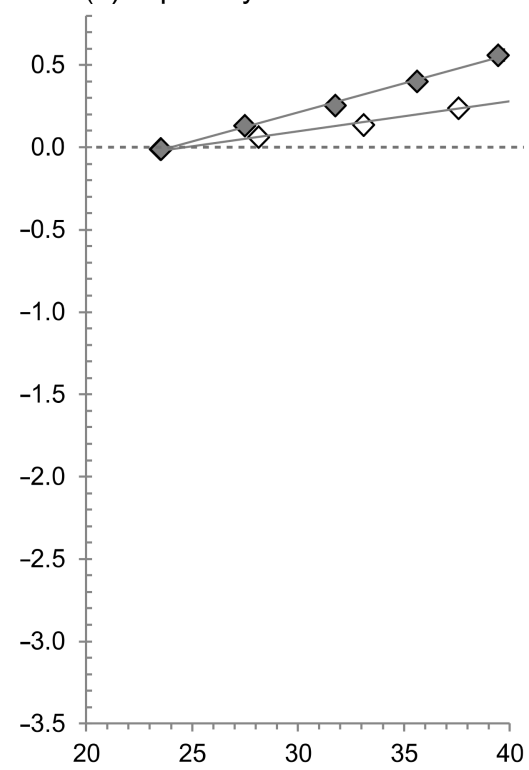

(e) Grant thermistor + tape
Figure 6. Magnitude of the local temperature disturbance caused by the surface skin temperature sensor and/or attachment and magnitude of the bias of the surface skin temperature sensor, each versus the model undisturbed temperature, under each air velocity condition $\left(0.2\right.$ and $\left.0.5 \mathrm{~m} \cdot \mathrm{s}^{-1}\right)$ and for each surface condition (a-e). Plotted data points and error bars are mean $\pm 95 \%$ confidence intervals (in some cases, the confidence intervals are too small to be visible in the figure); solid gray lines are regression lines fitted to mean data for illustrative purposes. Data beyond $40{ }^{\circ} \mathrm{C}$ (the last steady state for $0.2 \mathrm{~m} \cdot \mathrm{s}^{-1}$ air velocity) are not shown here to maintain emphasis on a physiological temperature range. $T_{\mathrm{d}}$, disturbed local surface temperature of the model; $T_{\mathrm{u}}$, undisturbed local surface temperature of the model.

\subsubsection{Measurement Bias}

When the surface of the skin model was warmer than the environmental air, the temperatures measured by the $T_{\text {sk }}$ sensors were consistently lower than both the $T_{\mathrm{u}}$ and $T_{\mathrm{d}}$. The magnitude of the bias increased in proportion to the difference between the model surface and environmental air temperatures (Figure 6). To gauge the relevance these biases at a realistic $T_{\text {sk }}$ reading, estimates are given in Table 1 to indicate the bias expected at a fixed $T_{\text {sk }}$ sensor temperature of $31^{\circ} \mathrm{C}$. The iButton without tape showed the greatest bias from both $T_{\mathrm{d}}$ and $T_{\mathrm{u}}$ with, for example, these un-taped iButtons measuring $31^{\circ} \mathrm{C}$ when 
the underlying $T_{\mathrm{d}}$ was $33.3^{\circ} \mathrm{C}$ and the corresponding $T_{\mathrm{u}}$ was $34.2^{\circ} \mathrm{C}$ (each at $0.5 \mathrm{~m} \cdot \mathrm{s}^{-1}$ air velocity). The custom thermistor and tape showed the least bias from both $T_{\mathrm{d}}$ and $T_{\mathrm{u}}$ with, for example, these custom thermistors measuring $31^{\circ} \mathrm{C}$ when the underlying $T_{\mathrm{d}}$ was $31.4{ }^{\circ} \mathrm{C}$ and the corresponding $T_{\mathrm{u}}$ was $31.3^{\circ} \mathrm{C}$ (each at $0.2 \mathrm{~m} \cdot \mathrm{s}^{-1}$ air velocity).

Table 1. Calculated estimates of bias (mean (95\% confidence intervals)) for a fixed surface skin temperature sensor of $31{ }^{\circ} \mathrm{C}$, expressed as difference from the disturbed reference temperature $\left(T_{\mathrm{d}}\right)$ and from the corresponding undisturbed reference temperature $\left(T_{\mathrm{u}}\right)$. Negative values for bias indicate the skin temperature sensor is cooler than the corresponding reference temperature.

\begin{tabular}{ccccc}
\hline & Custom Thermistor + Tape, ${ }^{\circ} \mathbf{C}$ & Grant Thermistor + Tape, ${ }^{\circ} \mathbf{C}$ & iButton + Tape, ${ }^{\circ} \mathbf{C}$ & iButton Only, ${ }^{\circ} \mathbf{C}$ \\
\hline $0.2 \mathrm{~m} \cdot \mathrm{s}^{-1}$ air velocity & & & & \\
$\quad$ Bias, from $T_{\mathrm{d}}$ & $-0.4(-0.5$ to -0.3$)$ & $-1.0(-1.3$ to -0.8$)$ & $-1.1(-1.1$ to -1.1$)$ & $-1.2(-1.2$ to -1.2$)$ \\
Bias, from $T_{\mathrm{u}}$ & $-0.3(-0.4$ to -0.3$)$ & $-1.4(-1.6$ to -1.2$)$ & $-1.3(-1.3$ to -1.2$)$ & $-1.6(-1.7$ to -1.6$)$ \\
$0.5 \mathrm{~m} \cdot \mathrm{s}^{-1}$ air velocity & & & & \\
$\quad$ Bias, from $T_{\mathrm{d}}$ & $-0.6(-0.6$ to -0.5$)$ & $-1.5(-2.0$ to -1.1$)$ & $-1.6(-1.7$ to -1.6$)$ & $-2.3(-2.4$ to -2.1$)$ \\
Bias, from $T_{\mathrm{u}}$ & $-0.3(-0.3$ to -0.2$)$ & $-1.8(-1.9$ to -1.6$)$ & $-1.4(-1.5$ to -1.4$)$ & $-3.2(-3.3$ to -3.1$)$ \\
\hline
\end{tabular}

\section{Discussion}

Given the impracticality of using human skin in vivo for frequent or detailed assessments or comparisons of $T_{\text {sk }}$ sensors, we sought to develop, evaluate, and utilize a synthetic skin model with realistic thermal properties as a benchtop alternative. There are two major outcomes from this work: First, the thermal skin model is promising for practical intersensor comparisons of common $T_{\mathrm{sk}}$ sensors (Grant thermistors and iButtons), although further work is required to understand why inter-sensor comparisons involving the custom $T_{\text {sk }}$ sensors were dissimilar for the skin model versus human trial. Second, the skin model can be used to gain insight into errors associated with $T_{\mathrm{sk}}$ measurement. In particular, this skin model facilitated the manifestation of local surface temperature disturbances when using $T_{\mathrm{sk}}$ sensors, and results indicated that measurements from those $T_{\mathrm{sk}}$ sensors typically differ from both the underlying disturbed surface temperature and from the temperature of that underlying surface in its undisturbed state (i.e., when not being measured by the $T_{\mathrm{sk}}$ sensor). Demonstrating and characterizing local temperature disturbances alongside measurement errors with a benchtop tool provides a practical platform from which to explore the magnitude of such effects for a variety of $T_{\mathrm{sk}}$ sensor types and, where relevant, explore error mitigation methods (e.g., corrections or new sensor design).

\subsection{Evaluation of Thermal Skin Model by Comparison with Human Trial}

Here we have assumed having no practical 'gold standard' human $T_{\text {sk }}$ measurement method. Accordingly, the skin model was evaluated by comparing the magnitude of mean inter-sensor differences determined on the skin model with the magnitude of those same inter-sensor differences determined on human skin during rest and cycling exercise. The skin model and the human trial were similar (within $0.4{ }^{\circ} \mathrm{C}$ ) for mean inter-sensor differences between the Grant thermistors and iButtons, although this was not so for the comparisons including the custom thermistor.

It should be noted first that inter-sensor differences in the human trial were calculated using a four-site (four-sensor) weighted-mean $T_{\mathrm{sk}}$, whereas the inter-sensor differences from the skin model experiments were calculated using single-site (single-sensor) measurements. This approach was considered reasonable here, because the tighter control of experimental conditions afforded in the skin model experiments meant that temperature variability was considerably lower; in the human trial, the greater site-to-site, momentto-moment variability is mitigated in part by averaging over the four sensors at the four body sites. Further, using weighted-mean $T_{\mathrm{sk}}$ is typical of human trials in the published literature and is typical in the assessment of thermal strain [3].

The similarity of the mean inter-sensor differences for the comparison between Grant thermistors and iButtons is an encouraging step in developing skin models that serve 
as practical, low-cost alternatives to human trials. An interesting observation was the closeness of the model-derived differences with $0.2 \mathrm{~m} \cdot \mathrm{s}^{-1}$ air velocity when compared to the human trial during periods where thermal sweating was not present (baseline rest, before the onset of sweating during fixed-load cycling, and from midway through recovery rest) and the closeness of the model-derived differences with $0.5 \mathrm{~m} \cdot \mathrm{s}^{-1}$ air velocity when compared to the human trial during periods where thermal sweating was present (fixed-load cycling after the onset of sweating; Figure 5). Indeed, considering only these combinations, $0.1{ }^{\circ} \mathrm{C}$ was the maximum difference (skin model vs. human trial) for mean differences between the Grant thermistors and iButtons.

The porous medical tape used throughout this work could be wetted during thermal sweating in the human trial, likely resulting in greater heat loss from the sensor via evaporative cooling $[28,41]$. Considering non-evaporative heat transfer when the air temperature is lower than the skin or surface temperature, a greater air velocity will result in greater heat loss from the $T_{\text {sk }}$ sensor. While not implemented for this purpose, it may be that the greater of the two air velocity conditions within the skin model experiments resulted in additional heat loss analogous to that associated with evaporative cooling in the human trial. If, indeed, the case for the conditions used in the present study, this observation is unlikely to be generalizable but does indicate that test conditions for the future use of skin models should encompass variations that mimic dry and wet surface conditions if dry and wet surface conditions are expected during actual end use. Key simplifications of the skin model used in this work included that the surface of the model was in a fixed horizontal position and perpendicular to forced convection, and there was no attempt to simulate sweating. Future work could be observational, such as investigating effects of model orientation and the presence of surface moisture that simulates sweating, or analytical by modeling various modes of heat and/or evaporative transfers, sensor sizes, underlying tissues, sensor materials, and transient conditions in addition to steady states.

The custom thermistor had the greatest accuracy (least bias versus $T_{\mathrm{u}}$ ) of the three $T_{\text {sk }}$ sensor types used here based solely on the outcome of the skin model experiments (Section 4.2), although this could not be translated to in vivo $T_{\text {sk }}$ measurements when considering the magnitude of relative differences: the mean differences of the custom thermistor versus each Grant thermistors and iButtons were larger using the skin model than when using human participants (Figure 5). Therefore, when an inter-sensor comparison involved the custom thermistor, it is possible that the differences were overestimated in the case of the skin model, the differences were mitigated in the case of the human trial, or a combination thereof.

A feature that could contribute to overestimation of differences (vs. custom thermistors) when using the skin model is that the same silicone elastomer was used for both the skin model and to encapsulate the custom thermistors ( $T_{\text {sk }}$ sensors), based on this material having thermal properties that reasonably approximates human skin [32,42]. The method of production meant that the top surface of the skin model and the bottom surface of the custom thermistor were each flat and smooth, and, in combination with being the same material, the thermal contact resistance may have been disproportionally low for the custom thermistor on the skin model compared to the custom thermistors on the human skin or compared to the Grant thermistors or iButtons on the skin model. Indeed, a practical observation during the experiments was that using the custom thermistors on the skin model created a kind of 'seal' at the model-senor interface.

In contrast, a feature that could contribute to mitigation of the inter-sensor differences (vs. custom thermistors) for human skin in vivo is the flexibility of the custom thermistors. The Grant thermistors and iButtons were each rigid (comprising stainless steel), and it was observed during the human trial that the iButtons and Grant thermistors appeared to depress into the skin more than the custom thermistors. Depression of a temperature sensor into the skin is associated with an otherwise higher measured temperature $[43,44]$, which is consistent with the Grant thermistors and iButtons being closer to the custom thermistors than would be estimated based on the skin model. Another possibility is 
the influence of moisture buildup under the sensor acting to decrease thermal contact resistance in the case of human skin versus 'dry' skin models. The use of an interfacial medium to simulate the buildup of moisture is recommended when using $T_{\mathrm{sk}}$ sensors with a metallic contact surface in combination with a physical model also with a metallic surface [22]. An interfacial medium was not used in the present study for a number of reasons, including that the skin simulant used here was not hard or incompressible like the metallic models used elsewhere [21,22,29-31] and so that the results presented here can act as a baseline, following which modification of other model variables can be investigated and compared. Indeed, the choice of interfacial medium may itself also influence the outcome. A skin model that allows surface wetting to simulate sweating or transepidermal water loss should obviate the need to consider other interfacial mediums.

It was encouraging that the mean inter-sensor differences among the three $T_{\text {sk }}$ sensors remained within $\pm 0.5^{\circ} \mathrm{C}$ in the human trial. That said, the measurement context of these relatively small differences was that the sensors were affixed to the participant using the same type of tape attachment, by the same experimenter in a systematized fashion, and with randomized relative placement of the sensors within each body site. Furthermore, all sensors were calibrated prior to use using the same instruments and processes. While this approach is expected within a method comparison study, such small differences cannot necessarily be expected when these mitigating factors are not also present, which is possible across different studies or measurement applications. Among 172 studies (published 2011-2016) involving physical activity, sport, or exercise and in which $T_{\mathrm{sk}}$ data were reported, the method of attachment was not reported or not clear in over half of those studies [10]. For over $90 \%$ of these studies, it was unclear whether the $T_{\text {sk }}$ sensors had been calibrated.

\subsection{Thermal Skin Model Use for Understanding Local Temperature Disturbance and Measurement Error}

The $T_{\mathrm{sk}}$ sensors investigated here exhibited linearly increasing bias concomitant with increasing surface-to-environment temperature gradient, a pattern consistent with previous work using aluminum models [21,22]. By using a skin model with thermal properties that better approximate human skin, the findings here expand on previous work by showing that using $T_{\text {sk }}$ sensors caused a local temperature disturbance and by delineating two distinct forms of bias: bias from $T_{\mathfrak{u}}$ and bias from $T_{\mathrm{d}}$ (Figure 1).

Our contention is that $T_{\mathfrak{u}}$ represents the best estimate of the 'true' surface temperature, and thus, it is bias from $T_{\mathrm{u}}$ that represents the best estimate of $T_{\mathrm{sk}}$ sensor systematic error during use. Bias from $T_{\mathrm{d}}$ is perhaps only important in that $T_{\mathrm{sk}}$ sensor systematic error (i.e., bias from $T_{\mathfrak{u}}$ ), itself, manifests from bias from $T_{\mathrm{d}}$ in combination with magnitude of the local temperature disturbance. The challenge here is that, in practice (outside the confines of these model experiments), it is only bias from $T_{\mathrm{d}}$ that is directly paired spatially and temporally with the $T_{\mathrm{sk}}$ sensor measurement, while the magnitude of the local temperature disturbance and the associated bias from $T_{\mathrm{u}}$ are somewhat hypothetical entities.

As indicated above, this characteristic of the current silicone elastomer model to facilitate local temperature disturbances contrasts metallic models in which local temperature effects are expected to be negligible due to the thermal conductivity being a different order of magnitude (e.g., aluminum $\sim 230 \mathrm{~W} /(\mathrm{m} \cdot \mathrm{K})$ versus human skin $\sim 0.2$ to $1.0 \mathrm{~W} /(\mathrm{m} \cdot \mathrm{K})$ ). One other experimental study had been located in which both the temperature bias and local modification were measured, although the surface sensor $T_{\mathrm{sk}}$ used in that experiment was designed for intermittent measurements, being manually held in place rather than being affixed in some way [45].

The thermal conductivity of the skin model used in this work $(\sim 0.23 \mathrm{~W} /(\mathrm{m} \cdot \mathrm{K}))$ was within the range of values reported for human skin, although at the lower end of this range [42]. Skin perfusion increases with increasing $T_{\text {sk }}$; hence, the effective thermal conductivity of the skin can approach or exceed $1 \mathrm{~W} /(\mathrm{m} \cdot \mathrm{K})$ when warm and highly perfused [42]. Accordingly, additives could be used to tailor the thermal properties of the current skin model to investigate if changing the thermal conductivity within the range 
of $\sim 0.2$ to $1.0 \mathrm{~W} /(\mathrm{m} \cdot \mathrm{K})$ influences the findings regarding local temperature disturbances and measurement biases. That said, previous numerical modeling indicated that, for an insulated $T_{\mathrm{sk}}$ sensor, the steady state skin surface temperature profiles were only negligibly influenced by perfusion rate [18].

In the present study, all sensors were attached using the same clinical tape, and the sensors were not vastly dissimilar in terms of physical size and shape. It would be useful for future work to include more diversity in the sensor setups being compared, from sensor systems smaller than those used here (e.g., [46]) through to sensors integrated into bulkier wearable devices such as 'smart' watches, bands, or patches [47]. From a practical perspective, this work justifies the ongoing development of sensor systems with the explicit intention of mitigating errors such as those described here. Reducing the size of the sensors is one way to mitigate errors, although such sensors must remain robust enough for practical use and need to balance reductions in size with susceptibility to point-to-point temperature variations within a local skin site. It is reasonable to expect that greater physical differences between sensor systems may lead to larger inter-sensor differences between those sensor systems, particularly during thermal sweating, so temperature data from larger devices must be treated with caution unless validity has been otherwise demonstrated.

Furthermore, only temperature steady states were considered in the present study; future work could include a time component with rates of temperature change that are physiologically relevant. Environmental temperatures other than the temperate conditions used here $\left(\sim 24^{\circ} \mathrm{C}\right)$ are equally important. That said, the linear relationships here between observed errors and the temperature difference between model surface and the environmental temperature are consistent with temperature errors in previous works [21,22], indicating that, all else equal, this temperature difference is, itself, more important than the absolute environmental temperature.

\subsection{Toward Universal Comparability and Long-Term Sustainability of Datasets}

In the present study, we have identified some idiosyncrasies of measurement system relevant for the quantification of $T_{\mathrm{sk}}$. More work is required to confirm that the local temperature disturbances and biases identified here are, indeed, representative of in vivo measurements; however, this work more widely illustrates that ongoing attention is required regarding the accurate acquisition of data in parallel with the end application of those data. Here, we have intentionally avoided specifying limits of practical relevance for measurement error, because the scope of this work was focused on understanding measurement errors independent of data end use. Future discussion is required around reasonable limits for acceptable error for given data end uses.

With contemporary interest in wearable technology, the increasing availability of large and personalized datasets, and the expanding potential of modeling physiological data for applications such as real-time feedback or predictive tools, the quality of the underlying data is important for establishing the quality of the use of that data. Efforts to understand and minimize errors or inconsistencies in measurement will be valuable, in that data models developed will need to be resistant to the propagation of errors, whereby small errors can become larger or more influential. Similarly, when considering the long-term sustainability of specific inferences, data models, or algorithms, it is clear that the outcome needs to be resistant to or independent of the specific measurement system used (e.g., types of temperature sensors and attachments) and to the effects of changing parts of a given measurement system with time (e.g., iterations of sensor or device design, material selection, changing commercial availability of parts). Independence of the measured value from the specific sensor system used also facilitates transfer of data or inferences to other parties.

One way forward is continuing to improve the measurement methods, whereby increasing the accuracy of sensors should lead to convergence of those sensor systems near the 'true' value for any given measurement context, or to the selection of specific sensor types that are shown to have superior validity. Another approach is having a standardized 
tool and method for baseline surface temperature measurements that allow intra- and inter-sensor measurements to be documented, reported, and tracked or compared over time. In principle, this establishment of baseline comparability should be encompassed via sensor calibration. However, the work here and elsewhere [22] illustrates that contact $T_{\mathrm{sk}}$ sensors calibrated by conventional means-that is, in a uniform thermal environment (e.g., water bath) - are still prone to errors when there is a temperature gradient across the measurement system, as is typically the case during measurement of human skin. A benchtop skin model is one candidate for this latter approach and can serve as a highly controlled medium for baseline surface comparisons that supplement conventional sensor calibration information and can supplement comparisons done in vivo [48].

Using human skin for assessing $T_{\mathrm{sk}}$ sensors increases the ecological validity of the findings but also has a number of practical and logistical constraints. Beyond resource and ethical considerations, one pertinent constraint is that comparisons of different sensors cannot be done both at the exact same site and time. This constraint also applies to other approaches including skin models; however, other physical and physiological factors complicate the situation in the case of measurements made in vivo. These factors include spatial heterogeneity of the underling tissues (e.g., dermis, epidermis, hypodermis, skeletal muscle, bone) or structures (blood vessels, sweat glands), effects of the orientation of the sensor (e.g., exposure to different local air movements), and interaction with sweat and associated evaporative cooling. This complexity of in vivo measurements, combined with the difficulty in determining what the 'true' reference temperature should be, supports the development of suitable skin models for practical intra- and inter-sensor comparisons and for understanding the impact of $T_{\mathrm{sk}}$ sensors on the skin itself during the measurement process.

\section{Conclusions}

The thermal skin model was suitable for replicating the in vivo inter-sensor mean differences for the comparison of two common $T_{\mathrm{sk}}$ sensors (iButtons and Grant thermistors; within $0.4{ }^{\circ} \mathrm{C}$ for in vivo vs. skin model) but not for those involving a third $T_{\text {sk }}$ sensor (custom thermistors). In speculation, this finding for comparisons involving the custom thermistors could be an anomaly due to the same material being used to make the skin model and to encapsulate the custom thermistors. Results from the skin model also demonstrate that using contact $T_{\mathrm{sk}}$ sensors can cause a local temperature disturbance and that those $T_{\mathrm{sk}}$ sensors become increasingly biased concomitant with an increasing surface-to-environment temperature gradient. Following the identification of two forms of $T_{\mathrm{sk}}$ sensor bias (bias from $T_{\mathrm{d}}$ and bias from $T_{\mathrm{u}}$ ), we contend that bias from $T_{\mathrm{u}}$ represents the best estimate of $T_{\mathrm{sk}}$ sensor systematic error during use, and accordingly, this form of bias is important for future sensor characterization, design, or correction. Accounting for evaporative heat transfers, changes in contact thermal resistance (i.e., buildup of moisture between skin and sensor) and further validation of model insights versus human skin are logical next steps for future work.

Author Contributions: Conceptualization, B.A.M., C.M.S., A.P., R.M.R. and S.A.; methodology, B.A.M. and S.A.; investigation, B.A.M.; formal analysis, B.A.M. and S.A.; resources, R.M.R. and S.A.; data curation, B.A.M.; writing-original draft preparation, B.A.M.; writing-review and editing, B.A.M., C.M.S., A.P., R.M.R. and S.A.; visualization, B.A.M.; supervision, C.M.S., R.M.R. and S.A.; project administration, B.A.M. and S.A. All authors have read and agreed to the published version of the manuscript.

Funding: This research received no external funding.

Institutional Review Board Statement: The study was conducted according to the guidelines of the Declaration of Helsinki, and approved by the Ethics Committee of Eastern Switzerland (Project ID: 2017-01376, EKOS 17/129; 16.08.2017).

Informed Consent Statement: Written informed consent was obtained from all participants involved in the study. 
Data Availability Statement: The data that support the findings of this study are available upon reasonable request.

Acknowledgments: The authors thank Rolf Stämpfli, Ankit Joshi, Shelley MacRae, Fabrizio Spano, Martin Camenzind, Jörg Gschwend, Peter Huber, Sebastian Lehner, Lina Zhai, and Afshin Abrishamkar for assistance and/or advice.

Conflicts of Interest: The authors declare no conflict of interest.

\section{Appendix A. Further Detail about the Thermal Skin Model}

Appendix A.1. Experimental Setup of the Thermal Skin Model

(a) Skin model and subsurface sensor placement

Top view: section with embedded sensors

Top view: full skin model

$300 \mathrm{~mm} \times 300 \mathrm{~mm} \times 10 \mathrm{~mm}$
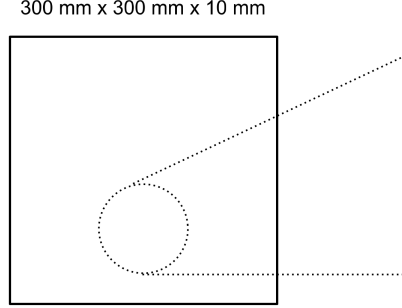

Surface skin temperature sensor (when used)

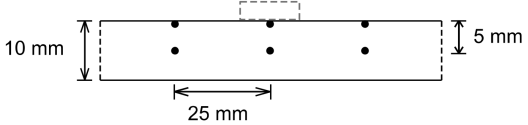

(b) Setup and air velocity

Forced air flow

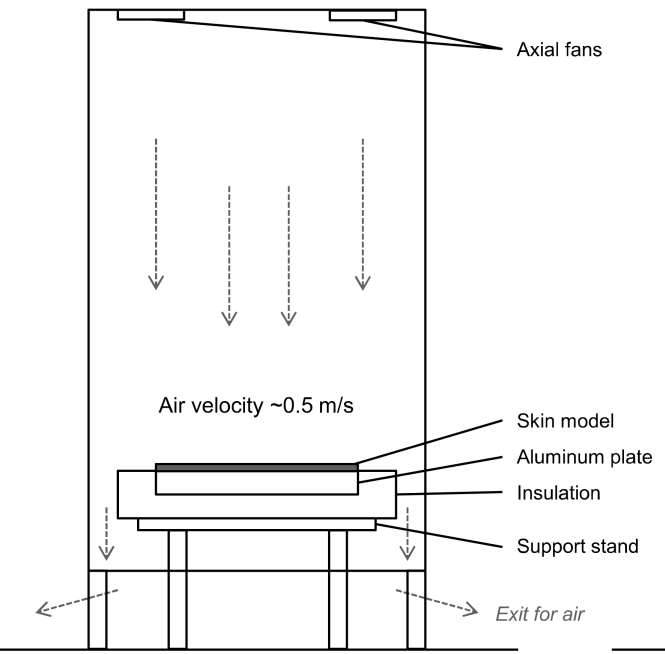

Air velocity $\sim 0.2 \mathrm{~m} / \mathrm{s}$

Figure A1. Setup of the silicone elastomer thermal skin model (a) and the overall setup for controlling the temperature (via water-perfused aluminum plate) and air velocity (fans or no fans (b)). The reference temperature used during this experiment was from the center of the three directly subsurface temperature sensors embedded in the skin simulant (a; see description in Appendix A.2, below). When a surface skin temperature sensor and/or attachment was used, it was positioned directly above the middle subsurface temperature sensor. The second row of sensors within the silicone elastomer skin ( $5 \mathrm{~mm}$ beneath the surface) enabled the estimation of temperature gradient through the model. 


\section{Appendix A.2. Establishing the Undisturbed Reference Temperature}

The thermal skin model was made with a row of three temperature sensors embedded directly beneath the surface of the skin model (Figure A1), because it was initially expected that the lateral sensors would be used as the $T_{\mathrm{u}}$ reference for the runs when the center sensor was, itself, covered by the surface $T_{\text {sk }}$ sensor and/or attachment (i.e., center sensor becoming $T_{\mathrm{d}}$ ). In order to designate the sensor(s) to be used as the $T_{\mathrm{u}}$ reference, data from the five experimental runs with no covering (i.e., bare skin model) were used to characterize the similarity between and within the three directly subsurface temperature sensors at each temperature steady state. The summary data from the uncovered runs, only, are given in Table A1. Considering the left and right subsurface sensors, the left was more consistent with the center subsurface sensor: mean differences across all steady states for this comparison were -0.01 to $-0.19^{\circ} \mathrm{C}$ for $0.2 \mathrm{~m} \cdot \mathrm{s}^{-1}$ air velocity and $<0.01$ to $0.02{ }^{\circ} \mathrm{C}$ for $0.5 \mathrm{~m} \cdot \mathrm{s}^{-1}$. However, the center subsurface sensor showed very little inter-run, withinsensor variation at each steady state, with the biggest absolute difference within any steady state being $0.05{ }^{\circ} \mathrm{C}$; all $\mathrm{SD}$ were $\leq 0.02{ }^{\circ} \mathrm{C}$. That is, the experimental setup and temperature steady states were found to be very consistent, with excellent run-to-run repeatability. Because these inter-run, within-sensor differences for the center reference sensor were so small, the mean values for the center subsurface steady states during these uncovered runs were used as the $T_{\mathfrak{u}}$ reference for all covered experimental runs. In this way, the $T_{\mathfrak{d}}$ and $T_{\mathfrak{u}}$ came from the identical sensor and position, albeit from separate experimental runs.

Table A1. Steady state mean temperatures $\left({ }^{\circ} \mathrm{C}\right)$ for the directly subsurface temperature sensors during the uncovered experimental runs (bare model surface) under each air velocity condition $\left(0.2\right.$ or $\left.0.5 \mathrm{~m} \cdot \mathrm{s}^{-1}\right)$. Data are mean (SD) for $\mathrm{n}=5$ replicates.

\begin{tabular}{ccccccc}
\hline & \multicolumn{2}{c}{$\mathbf{0 . 2} \mathbf{~ m} \cdot \mathbf{s}^{-\mathbf{1}}$ Condition } & \multicolumn{2}{c}{$\mathbf{0 . 5} \mathbf{~ m} \cdot \mathbf{s}^{-\mathbf{1}}$ Condition } \\
\hline \multirow{2}{*}{$\begin{array}{c}\text { Steady } \\
\text { state }\end{array}$} & \multicolumn{2}{c}{ Subsurface sensor position } & \multicolumn{2}{c}{ Subsurface sensor position } \\
\cline { 2 - 6 } & Center & Left & Right & Center & Left & Right \\
\hline 1 & $23.50(0.01)$ & $23.49(0.01)$ & $23.51(0.01)$ & $23.54(0.02)$ & $23.52(0.02)$ & $23.55(0.02)$ \\
2 & $28.21(0.01)$ & $28.16(0.01)$ & $28.16(0.01)$ & $27.59(0.02)$ & $27.59(0.02)$ & $27.48(0.02)$ \\
3 & $33.21(0.01)$ & $33.11(0.02)$ & $33.08(0.01)$ & $31.93(0.02)$ & $31.93(0.02)$ & $31.67(0.04)$ \\
4 & $37.76(0.01)$ & $37.62(0.02)$ & $37.55(0.02)$ & $35.89(0.02)$ & $35.89(0.02)$ & $35.47(0.03)$ \\
5 & $42.26(0.02)$ & $42.07(0.02)$ & $41.93(0.02)$ & $39.80(0.02)$ & $39.79(0.02)$ & $39.21(0.04)$ \\
\hline
\end{tabular}

\section{Appendix B. Calibration of Temperature Sensors}

All datasets from the calibration procedures were complete. Sensor-specific linear equations were satisfactory for correcting the raw temperature data, as indicated by a low typical error of the estimate (TEE; mean residual error from the fitted regression line) for each set of steady state vales.

- For the calibration of the thermistors embedded in the skin simulant $(\mathrm{n}=6)$, the TEE was $0.002-0.004{ }^{\circ} \mathrm{C}$.

- For the calibration of the Tsk sensors prior to the skin model experiments ( $\mathrm{n}=5$ for each sensor type), the TEE was: custom thermistors, $0.03-0.04{ }^{\circ} \mathrm{C}$; Grant thermistors, $0.01-0.02{ }^{\circ} \mathrm{C}$; and iButtons, $0.02-0.05^{\circ} \mathrm{C}$.

- For the calibration of the Tsk sensors prior to the human trial ( $\mathrm{n}=4$ for each sensor type), the TEE was: custom thermistors, all $<0.01{ }^{\circ} \mathrm{C}$; Grant thermistors, all $<0.01{ }^{\circ} \mathrm{C}$; and iButtons, $0.01-0.02{ }^{\circ} \mathrm{C}$.

\section{Appendix C. Estimating Thermal Skin Model Inter-Sensor Differences}

An example is given in Figure A2 illustrating:

- the estimation of the model surface temperature required to be approximately equivalent to a given period mean skin temperature from the human trial (in this example, the period immediately preceding the onset of sweating during fixed-load exercise), and 
- the estimation of temperature for each respective surface $T_{\mathrm{sk}}$ sensor (in this example, a Grant thermistor and custom thermistor), which is then used to calculate that particular inter-sensor difference.

For each $T_{\mathrm{sk}}$ sensor replicate under each skin model air velocity condition, this process was repeated at each model surface temperature that corresponded to a period mean skin temperature from the human trial.
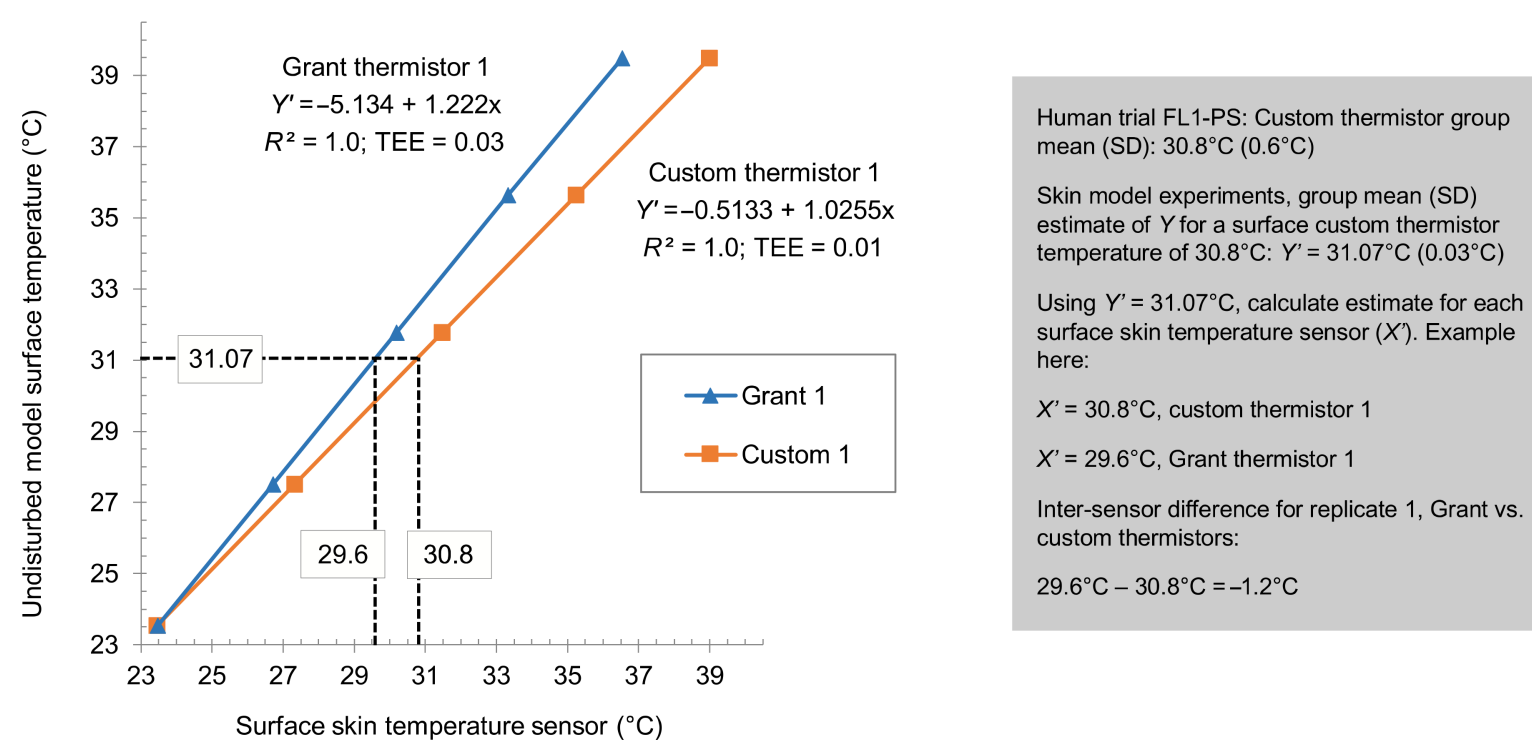

Figure A2. Estimation of required model surface temperature and resultant temperatures of the skin temperature sensors in an example inter-sensor comparison (Grant thermistor vs. custom thermistor). Plotted data are the first replicates for each respective skin temperature sensor in the skin model experiments under the air velocity condition of $0.5 \mathrm{~m} \cdot \mathrm{s}^{-1}$. See the main text (Section 2.5.3) for more information. FL1-PS, fixed-load cycling 1 pre-sweating; SD, standard deviation; $R^{2}$, coefficient of determination; TEE, typical error of the estimate.

\section{References}

1. Gagge, A.P.; Stolwijk, J.A.J.; Hardy, J.D. Comfort and thermal sensations and associated physiological responses at various ambient temperatures. Environ. Res. 1967, 1, 1-20. [CrossRef]

2. Nadel, E.R.; Bullard, R.W.; Stolwijk, J.A.J. Importance of skin temperature in the regulation of sweating. J. Appl. Physiol. 1971, 31, 80-87. [CrossRef] [PubMed]

3. International Organization for Standardization. ISO 9886: Ergonomics-Evaluation of Thermal Strain by Physiological Measurements; International Organization for Standardization: Geneva, Switzerland, 2004.

4. Pantelopoulos, A.; Bourbakis, N.G. A survey on wearable sensor-based systems for health monitoring and prognosis. IEEE Trans. Syst. Man Cybern. Part C 2010, 40, 1-12. [CrossRef]

5. Dias, D.; Paulo Silva Cunha, J. Wearable health devices-Vital sign monitoring, systems and technologies. Sensors 2018, $18,2414$. [CrossRef]

6. Rowell, L.B. Reflex control of the cutaneous vasculature. J. Investig. Dermatol. 1977, 69, 154-166. [CrossRef]

7. Zhang, H.; Arens, E.; Huizenga, C.; Han, T. Thermal sensation and comfort models for non-uniform and transient environments: Part I: Local sensation of individual body parts. Build. Environ. 2010, 45, 380-388. [CrossRef]

8. $\quad$ Eggenberger, P.; MacRae, B.A.; Kemp, S.; Bürgisser, M.; Rossi, R.M.; Annaheim, S. Prediction of core body temperature based on skin temperature, heat flux, and heart rate under different exercise and clothing conditions in the heat in young adult males. Front. Physiol. 2018, 9, 1-11. [CrossRef]

9. Bach, A.J.E.; Stewart, I.B.; Minett, G.M.; Costello, J.T. Does the technique employed for skin temperature assessment alter outcomes? A systematic review. Physiol. Meas. 2015, 36, R27-R51. [CrossRef] [PubMed]

10. MacRae, B.A.; Annaheim, S.; Spengler, C.M.; Rossi, R.M. Skin temperature measurement using contact thermometry: A systematic review of setup variables and their effects on measured values. Front. Physiol. 2018, 9, 1-24. [CrossRef]

11. Bedford, T.; Warner, C.G. On methods of measuring skin temperature. J. Hyg. 1934, 34, 81-98. [CrossRef]

12. Murlin, J.R. Skin temperature, its measurement and significance for energy metabolism. Ergebnisse Physiol. Bol. Chem. Exp. Pharmakol. 1939, 42, 153-227. [CrossRef]

13. Hardy, J.D. The radiation of heat from the human body: II. A comparison of some methods of measurement. J. Clin. Investig. 1934, 13, 605-614. [CrossRef] [PubMed] 
14. Stoll, A.M. Techniques and uses of skin temperature measurements. Ann. N. Y. Acad. Sci. 1964, 121, 49-56. [CrossRef] [PubMed]

15. Stoll, A.M.; Hardy, J.D. Direct experimental comparison of several surface temperature measuring devices. Rev. Sci. Instrum. 1949, 20, 678-686. [CrossRef] [PubMed]

16. Stoll, A.M.; Hardy, J.D. Study of thermocouples as skin thermometers. J. Appl. Physiol. 1950, 2, 531-543. [CrossRef]

17. Evans, J.P.; Wilson, R.E. A comparison of differential measurements of skin temperature using a radiometer, resistance thermometer, and thermocouples. J. Lab. Clin. Med. 1951, 38, 557-560. [PubMed]

18. Boetcher, S.K.S.; Sparrow, E.M.; Dugay, M. V Characteristics of direct-contact, skin-surface temperature sensors. Int. J. Heat Mass Transf. 2009, 52, 3799-3804. [CrossRef]

19. Buono, M.J.; Ulrich, R.L. Comparison of mean skin temperature using "covered" versus "uncovered" contact thermistors. Physiol. Meas. 1998, 19, 297-300. [CrossRef]

20. Tyler, C.J. The effect of skin thermistor fixation method on weighted mean skin temperature. Physiol. Meas. 2011, 32, 1541-1547. [CrossRef] [PubMed]

21. Psikuta, A.; Niedermann, R.; Rossi, R.M. Effect of ambient temperature and attachment method on surface temperature measurements. Int. J. Biometeorol. 2014, 58, 877-885. [CrossRef] [PubMed]

22. MacRae, B.A.; Annaheim, S.; Stämpfli, R.; Spengler, C.M.; Rossi, R. Validity of contact skin temperature sensors under different environmental conditions with and without fabric coverage: Characterisation and correction. Int. J. Biometeorol. 2018, 62, 1861-1872. [CrossRef]

23. van Marken Lichtenbelt, W.D.; Daanen, H.A.M.; Wouters, L.; Fronczek, R.; Raymann, R.J.E.M.; Severens, N.M.W.; Van Someren, E.J.W. Evaluation of wireless determination of skin temperature using iButtons. Physiol. Behav. 2006, 88, 489-497. [CrossRef]

24. Harper Smith, A.D.; Crabtree, D.R.; Bilzon, J.L.J.; Walsh, N.P. The validity of wireless iButtons(R) and thermistors for human skin temperature measurement. Physiol. Meas. 2010, 31, 95-114. [CrossRef] [PubMed]

25. Bach, A.J.E.; Stewart, I.B.; Disher, A.E.; Costello, J.T. A comparison between conductive and infrared devices for measuring mean skin temperature at rest, during exercise in the heat, and recovery. PLoS ONE 2015, 10, e0117907. [CrossRef]

26. McFarlin, B.K.; Venable, A.S.; Williams, R.R.; Jackson, A.W. Comparison of techniques for the measurement of skin temperature during exercise in a hot, humid environment. Biol. Sport 2015, 32, 11-14. [CrossRef] [PubMed]

27. Yakovlev, V.V.; Utekhin, B.A. Errors in skin temperature measurements due to changes in evaporation under the sensor. Bull. Exp. Biol. Med. 1965, 60, 1210-1212. [CrossRef]

28. MacRae, B.A.; Rossi, R.M.; Psikuta, A.; Spengler, C.M.; Annaheim, S. Contact skin temperature measurements and associated effects of obstructing local sweat evaporation during mild exercise-induced heat stress. Physiol. Meas. 2018, 39, 075003. [CrossRef] [PubMed]

29. Krause, B.F. Accuracy and response time comparisons of four skin temperature-monitoring devices. Nurse Anesth. 1993, 4, 55-61. [PubMed]

30. Lee, E.R.; Kapp, D.S.; Lohrbach, A.W.; Sokol, J.L. Influence of water bolus temperature on measured skin surface and intradermal temperatures. Int. J. Hyperth. 1994, 10, 59-72. [CrossRef]

31. James, C.A.; Richardson, A.J.; Watt, P.W.; Maxwell, N.S. Reliability and validity of skin temperature measurement by telemetry thermistors and a thermal camera during exercise in the heat. J. Therm. Biol. 2014, 45, 141-149. [CrossRef]

32. Zhai, L.; Spano, F.; Li, J.; Rossi, R.M. Development of a multi-layered skin simulant for burn injury evaluation of protective fabrics exposed to low radiant heat. Fire Mater. 2019, 43, 144-152. [CrossRef]

33. International Organization for Standardization. ISO 139: Textiles—Standard Atmospheres for Conditioning and Testing; International Organization for Standardization: Geneva, Switzerland, 2005.

34. International Organization for Standardization. ISO 5084: Textiles—Determination of Thickness of Textiles and Textile Products; International Organization for Standardization: Geneva, Switzerland, 1996.

35. British Standards Institution. BS EN 12127: Determination of Mass Per Unit Area Using Small Samples; British Standards Institution: London, UK, 1998.

36. International Organization for Standardization. ISO 9237: Textiles—Determination of the Permeability of Fabrics to Air; International Organization for Standardization: Geneva, Switzerland, 1995.

37. International Organization for Standardization. ISO 11092: Textiles_Physiological effects_Measurement of Thermal and Water-Vapour Resistance under Steady-State Conditions (Sweating Guarded-Hotplate Test); International Organization for Standardization: Geneva, Switzerland, 2014.

38. Ramanathan, N.L. A new weighting system for mean surface temperature of the human body. J. Appl. Physiol. 1964, 19, 531-533. [CrossRef]

39. Hopkins, W.G.; Marshall, S.W.; Batterham, A.M.; Hanin, J. Progressive statistics for studies in sports medicine and exercise science. Med. Sci. Sports Exerc. 2009, 41, 3-12. [CrossRef]

40. Santee, W.R.; Gonzalez, R.R. Characteristics of the thermal environment. In Human Performance Physiology and Environmental Medicine at Terrestrial Extremes; Pandolf, K.B., Sawka, M.N., Gonzalez, R.R., Eds.; Benchmark Press: Indianapolis, IN, USA, 1988; pp. 1-43.

41. Priego Quesada, J.I.; Martínez Guillamón, N.; de Anda, R.M.C.O.; Psikuta, A.; Annaheim, S.; Rossi, R.M.; Corberán Salvador, J.M.; Pérez-Soriano, P.; Salvador Palmer, R. Effect of perspiration on skin temperature measurements by infrared thermography and contact thermometry during aerobic cycling. Infrared Phys. Technol. 2015, 72, 68-76. [CrossRef] 
42. Xu, F.; Lu, T.J.; Seffen, K.A.; Ng, E.Y.K. Mathematical modeling of skin bioheat transfer. Appl. Mech. Rev. $2009,62,050801$. [CrossRef]

43. Jirak, Z.; Jokl, M.; Stverak, J.; Pechlat, R.; Coufalov, H. Correction factors in skin temperature measurement. J. Appl. Physiol. 1975, 38, 752-756. [CrossRef]

44. Mahanty, S.D.; Roemer, R.B. The effect of pressure on skin temperature measurements for a disk sensor. J. Biomech. Eng. 1979, 101, 261-266. [CrossRef]

45. Mahanty, S.D.; Roemer, R.B. Skin temperature probe. J. Biomech. Eng. 1979, 101, 232-238. [CrossRef]

46. Chen, Y.; Lu, B.; Chen, Y.; Feng, X. Breathable and stretchable temperature sensors inspired by skin. Sci. Rep. $2015,5,11505$. [CrossRef]

47. Peake, J.M.; Kerr, G.; Sullivan, J.P. A critical review of consumer wearables, mobile applications, and equipment for providing biofeedback, monitoring stress, and sleep in physically active populations. Front. Physiol. 2018, 9, 1-19. [CrossRef] [PubMed]

48. Havenith, G.; Lloyd, A.B. Counterpoint to "Infrared cameras overestimate skin temperature during rewarming from cold exposure". J. Therm. Biol. 2020, 92, 102663. [CrossRef] [PubMed] 